\title{
The Generation of an Engineered Interleukin-10 Protein With Improved Stability and Biological Function
}

\author{
Faisal Minshawi ${ }^{1,2 *}$, Sebastian Lanvermann ${ }^{3}$, Edward McKenzie ${ }^{4}$, Rebecca Jeffery ${ }^{2}$, \\ Kevin Couper ${ }^{2}$, Stamatia Papoutsopoulou ${ }^{2,5}$, Axel Roers ${ }^{6}$ and Werner Muller ${ }^{2 *}$ \\ ${ }^{1}$ Department of Laboratory Medicine, Faculty of Applied Medical Sciences, Umm Al-Qura University, Makkah, Saudi Arabia, \\ ${ }^{2}$ Lydia Becker Institute of Immunology and Inflammation, University of Manchester, Manchester, United Kingdom, ${ }^{3}$ Centre for \\ Translational Medicine, Thomas Jefferson University, Philadelphia, PA, United States, ${ }^{4}$ Manchester Institute of Biotechnology, \\ Faculty of Science and Engineering, University of Manchester, Manchester, United Kingdom, ${ }^{5}$ Department of Cellular and \\ Molecular Physiology, University of Liverpool, Liverpool, United Kingdom, ${ }^{6}$ Institute of Immunology, Medical Faculty Carl \\ Gustav Carus, University of Technology Dresden, Dresden, Germany
}

Interleukin-10 (IL-10) is an immunoregulatory cytokine that plays a pivotal role in modulating inflammation. $\mathrm{IL}-10$ has inhibitory effects on proinflammatory cytokine

OPEN ACCESS

Edited by:

Fulvio D'Acquisto,

University of Roehampton London, United Kingdom

Reviewed by:

Krishna Rajarathnam, University of Texas Medical Branch at Galveston, United States Maria Laura Belladonna,

University of Perugia, Italy

*Correspondence: Faisal Minshawi

fominshawi@uqu.edu.sa Werner Muller

Werner.Muller@manchester.ac.uk

Specialty section:

This article was submitted to Inflammation,

a section of the journal

Frontiers in Immunology

Received: 14 May 2020

Accepted: 06 July 2020

Published: 11 August 2020

Citation:

Minshawi F, Lanvermann S, McKenzie E, Jeffery R, Couper K,

Papoutsopoulou S, Roers A and Muller W (2020) The Generation of an Engineered Interleukin-10 Protein With Improved Stability and Biological

Function. Front. Immunol. 11:1794 doi: 10.3389/fimmu.2020.01794 production and function in vitro and in vivo; as such, IL-10 is viewed as a potential treatment for various inflammatory diseases. However, a significant drawback of using $\mathrm{IL}-10$ in clinical application is the fact that the biologically active form of IL-10 is an unstable homodimer, which has a short half-life and is easily degraded in vivo. Consequently, IL-10 therapy using recombinant native IL-10 has had only limited success in the treatment of human disease. To improve the therapeutic potential of $\mathrm{IL}-10$, we have generated a novel form of IL-10, which consists of two IL-10 monomer subunits linked in a head to tail fashion by a flexible linker. We show that the linker length per se did not affect the expression and biological activity of the stable IL-10 molecule, which was more active than natural IL-10, both in vitro and in vivo. We confirmed that the new form of IL-10 had a much-improved temperature- and $\mathrm{pH}$-dependent biological stability compared to natural IL-10. The IL-10 dimer protein binds to the IL-10 receptor similarly to the natural IL-10 protein, as shown by antibody blocking and through the genetic modifications of one monomer in the IL-10 dimer specifically at the IL-10 receptor binding site. Finally, we showed that stable IL-10 is more effective at suppressing LPS-inducedinflammation in vivo compared to the natural IL-10. In conclusion, we have developed a new stable dimer version of the IL-10 protein with improved stability and efficacy to suppress inflammation. We propose that this novel stable IL-10 dimer could serve as the basis for the development of targeted anti-inflammatory drugs.

Keywords: interleukin-10, immunoregulation, inflammation, cytokine, covalent linker, stable dimer

\section{INTRODUCTION}

IL-10 is a pleiotropic cytokine that is produced by different cell types, including myeloid cells (dendritic cells, macrophages, eosinophils, neutrophils, and mast cells) and lymphoid cells (NK, $\mathrm{B}$ cells, and $\mathrm{T}$ cells) with broad anti-inflammatory activity. Macrophages and myeloid dendritic cells express IL-10 upon activation of MyD88 and TRIF-dependent TLR pathways such as TLR3 
and TLR4, by stimulation with dsDNA and LPS, respectively (1). Moreover, tolerogenic dendritic cells (CD11 $c^{\text {low }}$ CD $45 R^{\text {high }}$ ) produce large amounts of IL-10 in response to LPS, which induces T regulatory cell development $(2,3)$. Natural regulatory cells (nTreg) produce IL-10 in the response to IL-2, which is vital for immune homeostasis (4).

Structurally, IL-10 belongs to the class II cytokine family, which involves IL-19, IL-20, IL-22, IL-24 (Mda-7), IL-26, and interferons (IFN- $\alpha,-\beta$, and $-\gamma$ ) (5). The IL-10 is a member of helical cytokines as an IL-10 monomer consists of six $\alpha$-helices (A-F) (6). Biologically active IL-10 is a non-covalent homodimer, which is described as a three-dimensional (3D) domain swapping protein with a molecular mass of $37 \mathrm{kDa}(18.5 \mathrm{kDa}$ for each one) (7-9). The IL-10 receptor (IL-10R) is a member of the class II cytokine receptor family and consists of two subunits, IL-10R1 and IL-10R2 $(10,11)$. IL-10 binds to IL-10R with high affinity; however, it can be species-specific. For example, mouse IL-10 was able to block the binding of human IL-10 to mouse cells but not human cells (12). Analysis of the protein crystal formed of IL-10 bound to soluble IL-10R1 revealed that the 3D domain-swapped homodimer IL-10, which consists of helices $\mathrm{E}$ and F from one chain inserted into the hydrophobic cleft formed by into helices A-D of the other chain, is essential for receptor-binding (13). IL10 binding to the IL-10R complex activates a Janus kinase- Signal Transducers and Activation Transcription system (JAK/STAT) signaling pathway. IL-10/IL-10R promotes phosphorylation and activation of the transcription factor STAT3, which is required for the IL-10 immunoregulatory effect (14).

The anti-inflammatory activity of IL-10 is in part due to the inhibition of the synthesis of pro-inflammatory cytokines such as tumor necrosis factor (TNF) (15). Furthermore, IL10 downregulates MHC class II expression and helps to promote wound healing $(5,16)$. The IL-10 showed to have an immunoregulatory effect during an infection with Toxoplasma gondii (17), Mycobacterium spp. (18), Herpes simplex virus (19), and malaria (20) by ameliorating the exaggerated $\mathrm{T}$ helper 1 and $\mathrm{CD}^{+} \mathrm{T}$ cells response including. A defect of IL-10 or the IL-10 receptor has been linked to excessive immune reactions and a disposition to chronic inflammatory disease, such as the early onset of inflammatory bowel disease (21-23). Also, changes of the gut microflora could lead to a change in the regulation of the gut-associated immune system, resulting in chronic gut inflammation, which in part could be the result of dysregulated IL-10 expression $(21,24)$.

Here we report the generation of a new form of IL-10 more suitable for therapeutic intervention, as the natural IL-10 has only a short half-life in vivo. The stability of the non-covalent IL-10 dimer strongly depends on physical parameters such as temperature and $\mathrm{pH}$. The IL-10 dimer dissociates to a monomeric form at low protein concentrations or at acidic $\mathrm{pHs}$, as typically found in inflamed tissue. Acidic $\mathrm{pH}$ has been found, for instance, in fracture-related hematomas (ranging as low as $\mathrm{pH} 4.7$ ), in cardiac ischemia ( $\mathrm{pH}$ 5.7) (25). Examinations of inflamed skin showed $\mathrm{pH}$ values of 5.8-7.2 (25-27). It has been demonstrated that $\sim 10$ and $\sim 50 \%$ of human IL-10 was dissociated (i.e., decayed) when heated to 37 and $55^{\circ} \mathrm{C}$, respectively, for $1 \mathrm{~h} \mathrm{(9).}$ Moreover, to date, the free IL-10 monomer has not been found in the solution. The IL-10 monomer could not exist in solution due to the presence of significant hydrophobic residues, which are shielded by interaction involved in the dimer form (6). Therefore, we reasoned that the generation of a stabilized dimer form of IL-10 might be a promising approach to overcome the inherent IL-10 instability and thereby improve its therapeutic potential.

One way to improve the stability of the IL-10 structure has been proposed by generating a stable IL-10 dimer using an internal flexible linker (28). Expressing the dimer as a single continuous fusion protein in which the monomers are connected by a flexible linkers (Gly-Ser) may offer a stability advantage and improve biological activity (29). Moreover, Gly-Ser linkers in recombinant proteins could play a general role in overall stability and solubility. A previous study has shown that using a Gly-rich linker to tether the dimeric forms of HIV-1 proteases (HIV-PR) results in a more stable form compared to the natural HIV-PR at pH 7.0 (30). Moreover, Foss et al. showed that using flexible linkers (Gly-rich linker) in transthyretin, the carrier of the thyroid hormone, is more stable than the natural after urea treatment (31). We now generated a functional IL-10 by linking two monomers using a flexible linker. We examined and compared the biological activity of the stable IL-10 dimer against the natural or non-covalently linked IL-10, both in vitro and in vivo. Here, we demonstrate that novel recombinant IL-10 dimer has improved stability and higher biological activity; therefore, it has the potential to be a building block for future IL-10 based immunotherapy treatment regimes.

\section{METHODS}

\section{Plasmid Design and IL-10 Construct}

The eukaryotic expression vector pCEP V19 was used to express the cDNA of natural mouse IL-10 (Nm) and stable mouse IL-10 (STm). The C-terminus of pCEP V19 includes Factor XA (FXA), human serum albumin (HSA), thrombin. oriP: replication origin of Epstein-Barr virus, EBNA-1: EpsteinBarr virus nuclear antigen-1, ampicillin: ampicillin resistance gene ( $\beta$-lactamase), pUC ori: the bacterial origin of replication, puromycin: puromycin resistance gene, CMV: Promoter of cytomegalovirus, BM40: a signal sequence of protein BM40, 8 His tag: 8 histidine residues, thrombin: thrombin, NheI, Bsu36I, BamHI: restriction sites, mouse IL-10 cDNA, SV40 pA: polyadenylation signal of SV40 Virus. The expression vector was generated and provided to us by Manuel Koch (Institute of Biochemistry II, University of Cologne). The nine amino acids $\left(-\mathrm{G}_{3} \mathrm{SG}_{4} \mathrm{~S}-\right)$ and 13 amino acid linker(- $\left.\mathrm{G}_{3} \mathrm{SG}_{4}-\mathrm{SG}_{4}{ }^{-}\right)$were generated by inserting the synthetic insert into the second monomer of mouse IL-10. The stable IL-10 cDNA was digested with the BamHI enzyme before ligating the synthetic inserts containing a nine and 13 amino acid linker with $5^{\prime}$ BamHI restriction site and $3^{\prime}$ BglII restriction sites. The confirmation of the correct insert orientation was carried out using NheI and BamHI restriction digestion. The stable human IL-10 (STh), and mutant cDNAs of mouse IL-10 were synthesized (GeneArt Gene Synthesis: Thermofisher). Oligonucleotides were cloned into pMA-RQ, Col E1 origin: the bacterial origin of replication, ampicillin: ampicillin resistance gene ( $\beta$-lactamase) 
(Thermofisher), then subcloned into the eukaryotic expression vector PCEP V19.

\section{Transfection of $\mathrm{HEK}_{293}$ EBNA, IL-10 Expression, and Purification}

$\mathrm{HEK}_{293}$ EBNA (HEK) mammalian cell line was generated from human embryonic kidney cells. The cell line was maintained in Dulbecco's modified Eagle's medium (DMEM) with 4.5 $\mathrm{g} / \mathrm{L}$ glucose, $10 \%$ fetal bovine serum (FBS) (Life Technologies Ltd), $1 \%$ L-Glutamine, and 1\% Penicillin-Streptomycin (PenStrep) (Sigma). HEK cells carry the Epstein-Barr Virus Nuclear Antigen-1 (EBNA-1) gene and allow for improved protein production since plasmids replicate competently in positive cells. HEK cells were transfected using Lipofectamine 3000 (Invitrogen). HEK cells were first seeded at $1 \times 10^{6}$ cells/well in a 6-well plate. Upon reaching a confluence of $\sim 80-90 \%, 5$ $\mu \mathrm{g}$ of the plasmid DNA was mixed with different volumes of lipofectamine $3000(3.5$ and $7.5 \mu \mathrm{l})$ in $125 \mu \mathrm{l}$ of Opti-MEM ${ }^{\mathrm{TM}}$ (Thermofisher), and the mixture was incubated for $15 \mathrm{~min}$ at room temperature. Afterward, the lipo-DNA mixture was added dropwise onto the cells. After $24 \mathrm{~h}$, the cells were washed once with PBS, and selection media containing puromycin (Gibco) was added (DMEM, 10\% FBS, 1\% Pen-Strep, 1\% of L-Glutamine, $(2 \mu \mathrm{g} / \mathrm{mL})$ and incubated for 3 days. The cells were then washed with PBS before adding fresh medium minus puromycin. The supernatant was harvested and stored at $-20^{\circ} \mathrm{C}$ until further use. The transfected cell supernatant was loaded at $4^{\circ} \mathrm{C}$ onto a HisTrap HP column (GE Healthcare). The column was then washed with $10 \mathrm{CV}$ of binding buffer, followed by stepwise elution of the protein with increasing imidazole concentration $(50,100,250$, and $500 \mathrm{mM})$ in binding buffer. Protein content and purity of each fraction were visualized by Coomassie staining. Positive fractions were pooled and dialyzed at $4^{\circ} \mathrm{C}$ against PBS.

\section{Animal Models}

Cells derived from mice that were used in the in vitro experiments were housed at the University of Manchester Biological Services Facility (BSF) under specific-pathogenfree conditions. They had easy access to food and water on a 12/12-h light cycle. All breeding mice were routinely screened (3 monthly or annually where applicable) according to BSF recommendations. The mouse strains (hTNF.LucBAC and C57BL/6) were bred in this study under a Home Office project license (70/7800) (P8829D3B4) in agreement with the Animal (Scientific Procedures) Act 1986. The C57BL/6 mice were ordered from Charles River (Charles River Laboratories, Inc., Harlow, UK). The in vivo experiments were performed at the University of Cologne, Germany, under animal experimental license 24-9168.11-1/2009-22.

\section{Purification of Bone Marrow-Derived Macrophages}

Mouse bone marrow-derived macrophages cells (BMDMs) were isolated, as described previously (32). Briefly, bone marrow-cells were dissected from femurs and tibiae and plated into a complete media (RPMI 1640 medium (Sigma) supplemented with $10 \% \mathrm{v} / \mathrm{v}$ FBS (Life Technologies Ltd), $100 \mathrm{IU} / \mathrm{mL}$ penicillin $100 \mu \mathrm{g} / \mathrm{mL}$ streptomycin (Sigma), $50 \mathrm{ng} / \mathrm{mL}$ mouse colony-stimulating factor (MCSF) (Promega), and $50 \mu \mathrm{M} \beta$-mercaptoethanol) (Sigma) at $5 \times 10^{6}$ cells per $90 \mathrm{~mm}$ bacterial petri dish (Sterilin, UK) for 4 days. On day $4,10 \mathrm{~mL}$ of complete media was added and incubated for 3 days. Adherent cells were then harvested with $5 \mathrm{~mL}$ of PBS supplemented with $5 \% \mathrm{v} / \mathrm{v}$ FBS and $2.5 \mathrm{mM}$ EDTA. For splenocyte isolation, the spleen was homogenized and filtered through nylon mesh filters $(70 \mu \mathrm{M}$; Becton Dickinson, UK) to generate a single-cell suspension. RBCs were lysed with ammonium chloride potassium (ACK) lysis buffer before the cell pellet was resuspended in DMEM medium supplemented with $10 \% \mathrm{v} / \mathrm{v} / \mathrm{FBS}, 1 \% \mathrm{w} / \mathrm{v} /$ Penicillin/Streptomycin, $1 \mathrm{mM}$ glutamine and $50 \mu \mathrm{M} \beta$-mercaptoethanol.

\section{Cell-Based Luciferase Reporter Assay}

The cell-based luciferase reporter assay has been previously described (32). BMDMs were plated in 96 well plates (OptiPlate96, White Opaque 96-well Microplate; Perkin Elmer, UK) at $1 \times 10^{5} /$ well in $0.1 \mathrm{~mL}$ medium containing $1 \mathrm{mM}$ luciferin (Promega) and left to rest overnight. Cells were stimulated with LPS (Salmonella enterica serovar Minnesota R595; Alexis Biochemicals, UK) $(10 \mathrm{ng} / \mathrm{mL})$ alone or in the presence of commercial mouse IL-10 mouse (Protech), natural or stable IL10 proteins. The anti-IL-10R antibody (clone: 1B1.3a) (Biolegend UK Ltd) was used to validate that the alteration in the luciferase response observed was dependent on the IL-10 receptor's engagement with IL-10. Unstimulated cells were used as a negative control. The luciferase activity was measured over time in a $\mathrm{CO}_{2}$ Lumistar Omega luminometer (BMG Labtech, UK).

\section{Temperature- and pH-Dependent Stability Study}

Stability experiments were performed as previously described (9), with the biological activity of IL-10 being monitored by luciferase assay. Briefly, $0.1 \mu \mathrm{g} / \mathrm{mL}$ of IL-10 sample was incubated at $55^{\circ} \mathrm{C}$ in time-course (to $30 \mathrm{~min}$ ). The pre-heated IL-10 sample was added together with LPS on hTNF.LucBAC BMDMs and the luciferase activity was monitored over time. The $\mathrm{pH}$-effect on the biological stability was determined by first pre-incubating a $0.1 \mu \mathrm{g} / \mathrm{mL}$ sample in different $\mathrm{pH}$ buffers (sodium citrate $\mathrm{pH} 2.5$, sodium phosphate $\mathrm{pH}$ 5.5-6.5 and TRIS-base $\mathrm{pH} 8.0-10.0$ ) for $24 \mathrm{~h}$ at $4^{\circ} \mathrm{C}$ followed by buffer exchange with PBS using a spin Desalting column (Thermofisher). Protein was diluted to a final concentration in each experiment of $10 \mathrm{ng} / \mathrm{mL}$ before testing for biological activity.

\section{Enzyme-Linked Immunosorbent Assay (ELISA) for IL-10}

The recombinant fusion mouse and human IL-10 proteins were detected after purification using Ready Set Go ELISA kits (Cat mIL-10 50-112 eBioscience, UK, Cat hIL-10 88-7106) according to the manufacturer instructions. Briefly, 96-well flat-bottom high-affinity ELISA plates were coated overnight at $4^{\circ} \mathrm{C}$ with the capture antibody. Plates were washed three times with washing buffer $(0.05 \%$ Tween 20 PBS) before the addition of blocking buffer to each well with 1X ELISA Diluent (supplied) for $1 \mathrm{~h}$. Standards were prepared and added in 2-fold serial 
dilutions (4,000-31.25 $\mathrm{pg} / \mathrm{mL})$ after washing the plate three times as above. The recombinant protein was diluted 100fold before serial dilution (1/2) were incubated for $2 \mathrm{~h}$ at RT. The detection antibody was added and incubated for $1 \mathrm{~h}$ after washing three times with washing buffer as above. Plates were further rewashed three times before incubation with streptavidinhorseradish peroxidase (HRP) for $30 \mathrm{~min}$ at RT. Plates were then washed five times with substrate solution, Tetramethylbenzidine (TMB). After incubation for another $15-30 \mathrm{~min}$ at RT in the dark, stop solution $\left(2 \mathrm{~N} \mathrm{H}_{2} \mathrm{SO}_{4}\right)$ was added $(25 \mu \mathrm{l})$ to each well. Optical density was measured using Versa-Max ELISA Microplate Reader with 450 filter.

\section{Western Blot}

Purified IL-10 was detected by western blot using the anti-mouse IL-10 (JES5-2A5) (eBiosciences). For Splenocytes $\left(5 \times 10^{6}\right)$ were either left unstimulated or were stimulated with either $\mathrm{Nm}$ or STm for $24 \mathrm{~h}$ After $24 \mathrm{~h}$ cells were washed three times with cold PBS and lysed in $0.5 \mathrm{~mL}$ of RIPA Buffer (Sigma) containing 5 ul of Protease Inhibitor Cocktail (Sigma) and incubated on ice for $5 \mathrm{~min}$. Samples were then centrifuged at 5,000 $\times \mathrm{g}$ for $5 \mathrm{~min}$, and the supernatants stored at $-20^{\circ} \mathrm{C}$. A nanodrop machine was used to determine the concentration of the protein (absorbance at $280 \mathrm{~nm}$ ) for each sample. The total protein concentration was adjusted in all samples with the addition of a RIPA lysis buffer.

Protein samples were loaded onto $4-12 \%$ BIS-Tris Gels (Invitrogen) using running buffer MED SDS (Invitrogen). $24 \mu \mathrm{l}$ of sample and $6 \mu \mathrm{l}$ of SDS Sample Buffer (4X) (Thermofisher) were mixed and heated at $80^{\circ} \mathrm{C}$ for $5 \mathrm{~min} .10 \mu \mathrm{l}$ of electrophoresis marker (Sigma) was used to determine the molecular size. The gel was run at $100 \mathrm{~V}$ until the tracking dye reached the bottom of the gel. The gel was removed from the gel cassettes and placed in the nitrocellulose membrane (Bio-Rad) and blotted using the Trans-Blot Turbo Transfer System (Bio-Rad). The blot was then incubated with blocking solution (5\% w/v milk in TBSTween) for $90 \mathrm{~min}$ at room temperature; before incubation with a primary antibody: anti-rat IL-10 (JES5-2A5) (eBiosciences), anti-mouse total STAT3 (Cell signaling), and anti-rabbit pSTAT3(Cell signaling) in 1:1000 in 5\% w/v milk in TBS-Tween overnight at $4{ }^{\circ} \mathrm{C}$. After that, the blots were washed four times with TBS-Tween for $20 \mathrm{~min}$; before incubated with the secondary antibody (horseradish-peroxidase (HRP)-conjugated goat antimouse or anti-rabbit (Cell signaling) at 1:2000 in 5\% w/v milk in TBS-Tween for $60 \mathrm{~min}$. The signals were developed using a Western Blot Chemiluminescent Substrate (ECL western blotting substrate (Cell signaling).

\section{In vivo Experiments}

Treatment of LPS-induced inflammation of the skin with IL-10: On three consecutive days, $10 \mu \mathrm{g}$ each of LPS in a volume of $50 \mu \mathrm{l}$, with or without varying amounts of Nm or STm, were injected into the flank at the same site. On the 5th day, the tissue surrounding the injection site became removed en bloc and hematoxylin and eosin ( $\mathrm{H} \& \mathrm{E}$ ) stained. The tissue in $4 \%$ formalin was cut to 5 microns thickness using a microtome. After drying the sections onto slides, the deparaffinization and rehydration stages were carried out. The preparations were subsequently stained with Mayer's hemalum solution (Sigma) and eosin (Sigma), dehydrated again, and covered with entellan (Merck). When viewed in the light microsphere, the basic cytoplasm, elastin, and collagen appeared red-orange, the nuclei dark blue, and erythrocytes yellow-orange.

Treatment of Endotoxin Shock by IL-10: $100 \mu \mathrm{l}$ PBS containing $25 \mu \mathrm{g}$ LPS (serotype 055: B5) was injected retroorbitally (i.v) in C57BL/6 mice (8-12 weeks) to indicate the optimum time for TNF synthesis after LPS treatment. To test the efficacy of IL-10 in TNF suppression, C57BL/6 mice were pretreated with different amounts of either PBS, Nm or STm $(2 \mu \mathrm{g}$ each) for $30 \mathrm{~min}$ before injecting LPS $(10 \mu \mathrm{g})$ At the indicated time points $(1.5,3$, or $6 \mathrm{~h})$, blood was taken retro-orbitally, and ELISA used to determine the TNF serum concentration. IL- $10^{-/-}$mice were given $10 \mu \mathrm{g}$ LPS together with increasing concentrations of $\mathrm{Nm}$ or STm being injected intravenously. After $3 \mathrm{~h}$, blood was withdrawn, and the IL 6 serum concentration determined by ELISA.

\section{Statistical Analysis}

Results were represented as the mean \pm standard error of the mean (SEM). Following assessment for normality and equality of variances, statistical inferences on data were performed using one-way, or two-way analysis of variance (ANOVA) followed by unpaired comparisons of treatment means using Dunnett's posthoc test (LPS-treated or vs. LPS+IL-10) used in the luciferase inhibition assay and (untreated or vs. treated) used in the stability study. Differences were considered statistically significant when $p<0.05$. Luciferase activity represented as area under the curve (AUC) Statistical analyses were performed using GraphPad Prism-7 Software Statistical Package, La Jolla CA; the USA.

\section{RESULTS}

\section{Generation, Expression, and Purification of a Stable IL-10 Protein Using a Mammalian Expression System}

The crystal structure of the IL-10 dimer shows that the Cterminus of one monomer is in close proximity to the $\mathrm{N}$ terminus of the second monomer due to $3 \mathrm{D}$ domain swapping with the antiparallel association. This suggested that a stabilized dimer could be generated by linking these two termini. A new recombinant stable IL-10 was generated by cloning two copies of the same IL-10 cDNA in tandem as a continuous polypeptide in the same orientation separated by 7 amino acids linkers $\left(-\mathrm{G}_{3} \mathrm{SG}_{3}-\right)$ (Figure 1A). Because glycine-serine linkers do not form $\alpha$-helices and have no reactive side chains (34), they are often used for a flexible and neutral connection of protein domains. Importantly, molecular dynamics simulation (Figure 1B) suggested that the linker would not interfere with the secondary structure of the monomers or IL-10 receptor binding site. In this report, we name the natural IL-10 (non-covalently linked) from mouse as $\mathrm{Nm}$ and human as Nh; besides, we name the stable IL-10 dimer from the mouse as STm and human as STh.

Both STm and Nm were generated from HEK cells with a His-tagged pCEP V19 expression vector. Recombinant Nm 


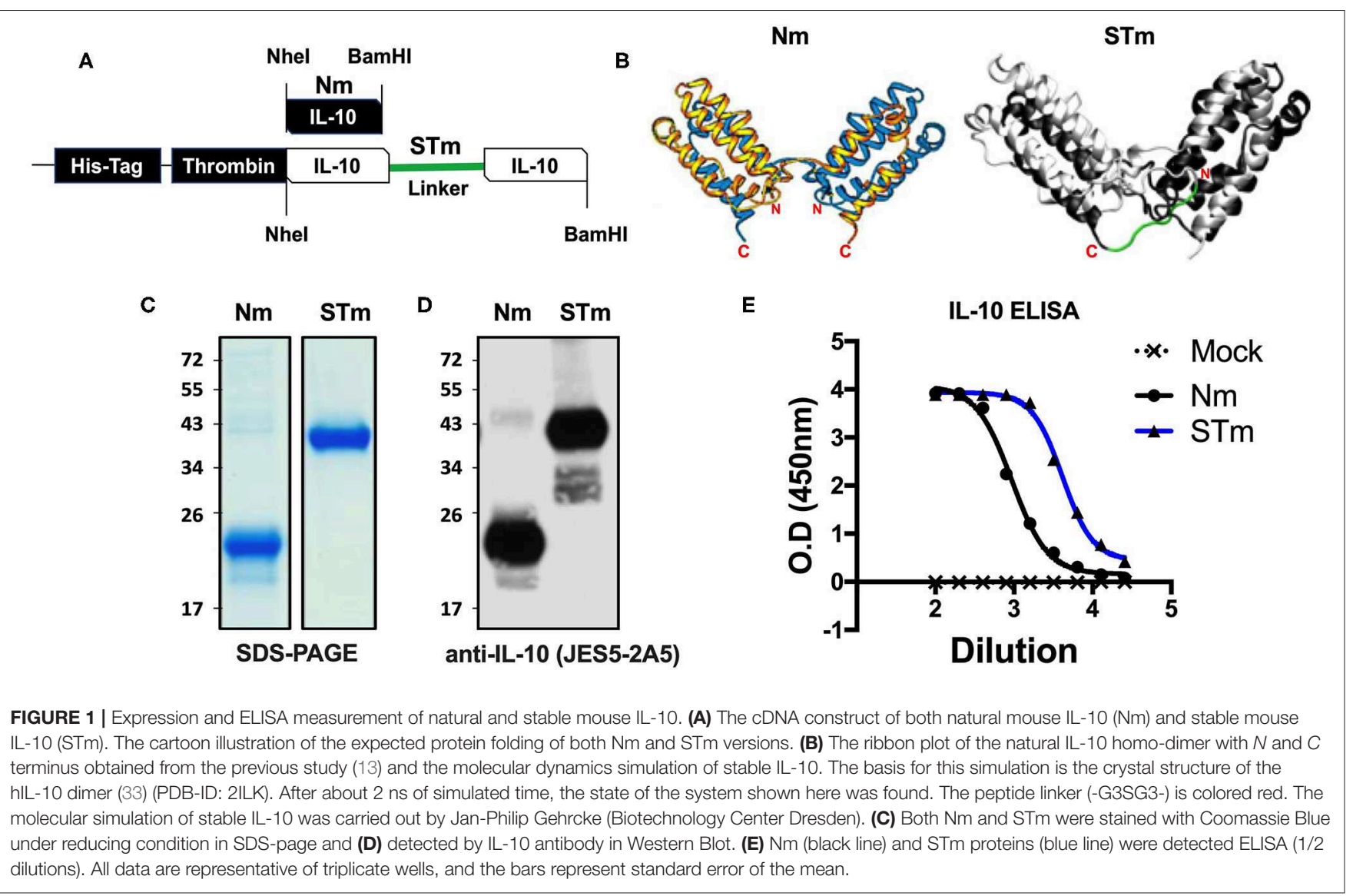

and STm proteins from parental vector-transfected cells were subjected to purification by an N-terminal His-tag purification column and analysis by SDS-PAGE and Western blotting. Under reducing conditions, the $\mathrm{Nm}$ migrated as a monomeric band in the region of $23 \mathrm{kDa}$, while the STm as a stable dimer migrated as a dimer band of $\sim 41 \mathrm{kDa}$ in SDS-PAGE (Figure 1C). This result corresponds to the calculated molecular weights of 18.7 for IL-10 monomers and $37.3 \mathrm{kDa}$ for IL-10 dimers, respectively (35). Both proteins were also detected using a specific IL-10 antibody (clone: JES5-2A5) in the western blot with different migration profiles due to the monomeric and dimeric forms (Figure 1D). Finally, both STm and Nm were detected by IL-10-ELISA to determine the recombinant IL-10 protein concentrations (Figure 1E) with a commercially sourced IL-10 protein (CmIL-10) (PeproTech) being used as an internal standard.

\section{The Biological Activity of Stabilized Mouse IL-10 Dimer in vitro}

Different approaches were used to measure the biological activities of the various versions of the IL-10 proteins we generated. First, we determined IL-10 activity by detection of STAT3 phosphorylation in IL-10 treated lymphocytes. To demonstrate proof of concept, spleen cells from wild-type, IL$10^{-/-}$, and IL-10R $1^{-/-}$mice were prepared and stimulated with the purified IL-10 proteins $(5 \mathrm{ng} / \mathrm{mL})$. Phosphorylated STAT3 (pSTAT3) $(75 \mathrm{kDa})$ was detected by western blot analysis of cell lysates. Both STm and Nm induced p-STAT3 in murine wildtype and IL- $10^{-/-}$but not in IL-10R $1^{-/-}$receptor-deficient cells (Figure 2A), demonstrating that the STm IL-10 uses the IL-10R for signaling.

We compared regulatory activities of STm, Nm, and commercial mouse IL-10 (CmIL-10) using BMDMs isolated from the hTNF.LucBAC reporter mouse reports the activation of the human TNF gene promoter, as previously described (32). STm, $\mathrm{Nm}$, and CmIL-10 (all at $10 \mathrm{ng} / \mathrm{mL}$ ) significantly suppressed the LPS-induced luciferase production by about 60\% $(p<0.001$ ANOVA) (Figure 2B) Subsequently, we titrated STm and Nm IL-10 and determined half-maximal suppression of luciferase induction $\left(\mathrm{ED}_{50}\right)$ values of 0.04 and $0.17 \mathrm{ng} / \mathrm{mL}$ for STm and $\mathrm{Nm}$, respectively (Figure 2C). For validation of this result, we isolated the supernatant of LPS- and IL-10-treated BMDMs after $24 \mathrm{~h}$ and measured soluble mouse TNF by ELISA. This alternative readout yielded $\mathrm{ED}_{50}$ values in the same range as obtained by quantification by the bioluminescence reporter system (Figure 2D). Thus, STm was 4 - to 8 -fold more active than natural IL-10. Likewise, Western blot analysis of STAT3 


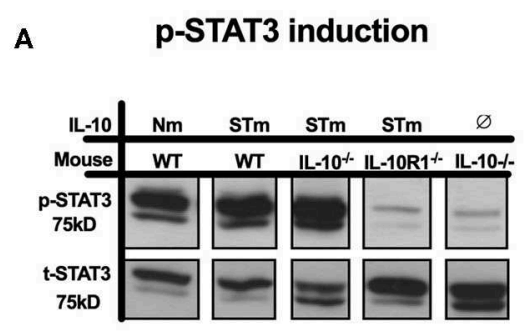

c

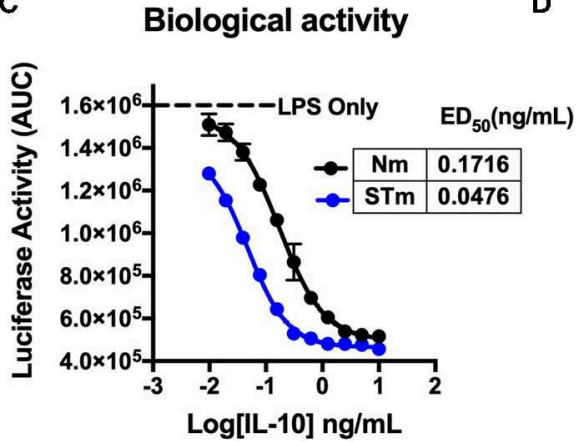

E

Dose-response of IL-10
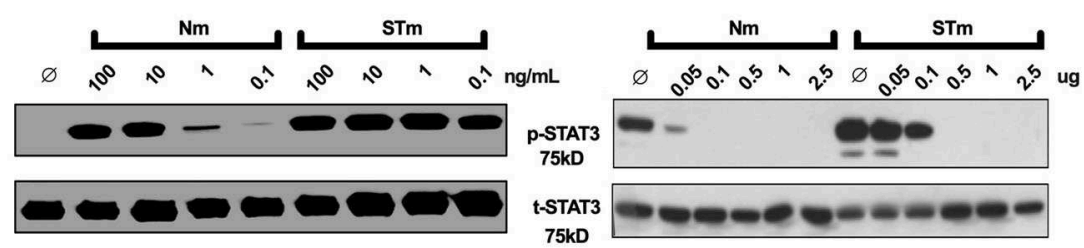

G

Anti IL-10R1 blocking

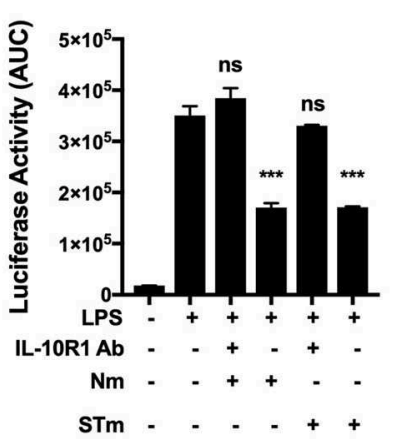

$\mathbf{F}$

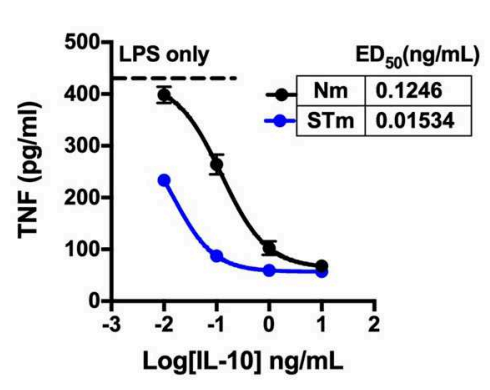

B

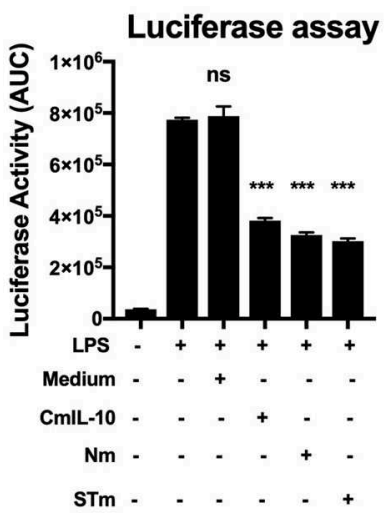

TNF

Anti IL-10 blocking

H

Biological activity

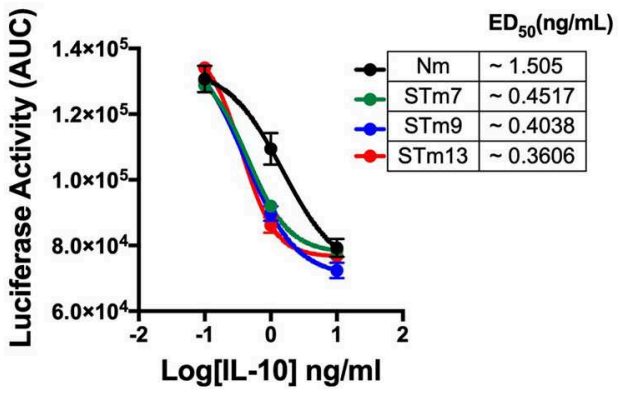

FIGURE 2 | Stable mouse IL-10 (STm) is biologically active in vitro. (A) Specific induction of STAT3 phosphorylation by STm (5 ng/mL) was verified by the use of spleen cells from different mouse lines: Wild type C57BL/6 (WT), IL-10 knockout (IL-10-/-) and IL-10 receptor knockout (IL-10R1-/-). (B) Luciferase activity was 
FIGURE 2 | monitored as the area under the curve (AUC) from BMDMs reporter mouse; cells were either unstimulated or stimulated with LPS (10 ng/mL) in the presence or absence of IL-10 from HEK 293 EBNA supernatants. A commercial mouse IL-10 (CmIL-10) was used as a positive control, and un-transfected cells supernatants (Medium) served as a negative control. Significant difference considered by comparing to LPS stimulated cells as follows: not significant (ns), ${ }^{* \star *} p<0.001$; ANOVA. (C) The dose-response effect of IL-10 on LPS-treated BMDMs of the transgenic mouse: the ED 50 of Nm (black line) and STm (blue line) was calculated as 0.17 and $0.04 \mathrm{ng} / \mathrm{mL}$, respectively. The maximum luciferase induction was determined by treating the BMDMs of the transgenic mouse with LPS alone at $10 \mathrm{ng} / \mathrm{mL}$ as it showed a black dot line. (D) Soluble mouse TNF was measured from the medium $24 \mathrm{~h}$ from BMDMs of the transgenic mouse either after LPS stimulation alone or after co-treating with either Nm (black line) or STm (blue line) in a dose-dependent fashion. (E) Splenocyte lysates of the C57BL/6 mouse were either unstimulated (Ø) or stimulated with IL-10 (Natural type or Stable) in a dose-dependent manner. (F) Inhibition of Nm and STm induced STAT3 phosphorylation by a blocking IL-10 antibody (clone JES5-2A5). IL 10 (2.5 ng) was mixed with the indicated amounts of antibody in one volume of $25 \mu$ l of medium and preincubated on ice for $30 \mathrm{~min}$ before adding this batch to $475 \mu \mathrm{l}$ of spleen cell suspension. (G) The Luciferase activity represented as AUC from LPS-induce cells from transgenic mouse were either unstimulated or treated with $0.2 \mu \mathrm{g} / \mathrm{mL}$ of the antill-10 receptor (antill-10Ra) antibody (clone 1B1.3a) for 30 min at $37^{\circ} \mathrm{C}$ before treatment with LPS $(10 \mathrm{ng} / \mathrm{mL})$ or LPS $(10 \mathrm{ng} / \mathrm{mL}), \mathrm{Nm}(10 \mathrm{ng} / \mathrm{mL})$, or STm (10 ng/mL). Furthermore, a significant difference is also calculated to compered Nm with STm after antill-10Ra treatment; ANOVA. (H) The dose-response stable IL-10 on LPS-treated BMDMs of transgenic mouse: the ED 50 of Nm (black line) is $1.5 \mathrm{ng} / \mathrm{mL}$ and the $\mathrm{ED}_{50}$ of STm proteins: STm7 (green) STm9 (blue line) and STm13 (red line) is calculated as $0.45 \mathrm{ng} / \mathrm{mL}$ and 0.40 and $0.38 \mathrm{ng} / \mathrm{mL}$ respectively. All data are representative of three independent experiments, with triplicate cultures per experiment $(N=3, n=3)$, and bars represent standard error of the mean.

phosphorylation induced by titrating amounts of IL-10 showed about 100-fold higher activity of STm compared to natural mouse IL-10 (Figure 2E). As a further test to quantify the biological activity of STm, we determined concentrations of anti-IL-10 mAb required to inhibit STm-induced STAT3 phosphorylation. While the activity of Nm was almost entirely blocked by pre-incubation with $0.05 \mathrm{mg} / \mathrm{ml}$ anti-IL-10 antibody, this antibody concentration did not affect STm activity (Figure 2F).

We believe that the suppression of luciferase is dependent on the IL-10R engagement with IL-10. Therefore, we tested the capability of the IL-10R antibody to block the effect of IL-10 on LPS-BMDMs of h.TNF.LucBAC. Our data showed that the presence of anti-IL-10R1 blocking antibodies completely blocked the biological activity of STm. Our data demonstrate that there is a non-significant change in the luciferase induction of a pretreated BMDMs with $0.2 \mu \mathrm{g} / \mathrm{mL}$ anti-IL-10 receptors antibody (antilL-10Ra) compared to the BMDMs treated with LPS only $(10 \mathrm{ng} / \mathrm{mL})$ (Figure 2G).

In order to address whether the length of the flexible linker, which may affect solubility, stability, and function of the fusion protein, we generated dimeric IL-10 molecules with different linker lengths $-\mathrm{G}_{3} \mathrm{SG}_{3}-(\mathrm{STm} 7),-\mathrm{G}_{3} \mathrm{SG}_{4} \mathrm{~S}$ - (STm9), and $-\mathrm{G}_{3} \mathrm{SG}_{4}-\mathrm{SG}_{4^{-}}$(STm13) as described above. Linker length did not impact on the bioactivity of the stable IL-10 as determined by suppression of LPS-induced TNF reporter expression (Figure 2H). Collectively, stable mouse IL-10 shows significantly more potent bioactivity compared to natural mouse IL-10.

\section{Temperature- and pH-Dependent Stability of Stable Mouse IL-10 Protein}

The human IL-10 homodimer was shown to rapidly dissociate into inactive monomers at lower $\mathrm{pH}$ and higher temperature (9). We compared the effect of temperature and $\mathrm{pH}$ on the biological activity of STm and $\mathrm{Nm}$. A $30 \mathrm{~min}$ incubation at $37^{\circ} \mathrm{C}$ did not affect the capacity of Nm or STm to suppress LPSinduced luciferase expression (Figure 3A). Nm lost bioactivity already upon $5 \mathrm{~min}$ exposure to $55^{\circ} \mathrm{C}$, whereas the treatment did not affect STm (Figure 3B, Figure S1A). $\mathrm{ED}_{50}$ of commercial IL-10 and Nm were significantly reduced by exposure to $55^{\circ} \mathrm{C}$ for $10 \mathrm{~min}$ while $\mathrm{STm}$ was not affected by this treatment (Figures 3C-E). Moreover, we investigate the impact of acidic and basic $\mathrm{pH}$ on the biological activity of IL-10 protein. Biological activity of both $\mathrm{Nm}$ and STm decreased in acidic and alkaline $\mathrm{pH}$ compared to neutral $\mathrm{pH}(\mathrm{pH} 7)$. However, at an acidic $\mathrm{pH}$ of 5 , STm was significantly more active over a wide concentration range (Figure 3F). We also addressed the effects of freezing and frozen storage on IL-10 bioactivity. Our data indicate that the ED50 of STm IL-10 was $0.041 \mathrm{ng} / \mathrm{mL}$, and $\mathrm{ED}_{50} \mathrm{Nm}$ was $0.15 \mathrm{ng} / \mathrm{mL}$ after storage at $-80^{\circ} \mathrm{C}$ for 6 months (Figure 3G). In summary, we show that stable mouse IL-10 is more resistant to heat and low $\mathrm{pH}$ than natural mouse IL-10.

\section{The Effect of the Site-Specific Mutation on Stable Mouse IL-10 Biology}

We predict that the STm bound to IL-10R like Nm (i.e., natural IL-10). To investigate this, we mutated the IL-10R binding site in the STm dimer. The location of the IL-10R binding site was obtained from the previous study on IL-10/IL$10 \mathrm{R}$ interaction (13). For this purpose, we introduced fourpoint mutations (L23G, R27G, K34G, and Q38G) at the helix $\mathrm{A}$ of the second monomer of the STm dimer (Figure 4A). This mutated form of IL- 10 named IL-10M2 ${ }^{\mathrm{Mu}}$. The IL-10 ELISA detected the IL-10M2 ${ }^{\mathrm{Mu}}$ as validation of the presence of the recombinant protein in culture supernatants of HEK cells (Figure 4B). The luciferase assay, represented as AUC, showed that $\mathrm{IL}-10 \mathrm{M} 2^{\mathrm{Mu}}(10 \mathrm{ng} / \mathrm{mL})$ inhibited the luciferase activity by $\sim 15 \%(p<0.5$, ANOVA). However, $50 \mathrm{ng} / \mathrm{mL}$ of IL-10M2 $2^{\mathrm{Mu}}$ inhibited luciferase activity by $\sim 40 \%$ as the $\mathrm{Nm}$ and STm $(p=0.001$, ANOVA) (Figure 4C). This data shows that maximal suppression could be achieved with 5-fold of IL- $10 \mathrm{M} 22^{\mathrm{Mu}}$ compared to STm and Nm. This experiment may represent the significance of dimerization in STm to retain the maximum activity by binding to the IL-10R as the natural IL-10.

In previous investigations, we demonstrated that several alanine substitutions in the IL-10 $0^{\mathrm{RRCHR}}$ (i.e., natural IL-10) region have an impact on the structural integrity ( $\alpha$-helical structure) of IL-10 (Figure 5A), with substitution of RRCHR to ARCHA causing the most significant loss of structure (36). Importantly, we found a correlation between changing the degree of $\alpha$-helical structure with the reduction in the biological activity of $\mathrm{Nm}$, as presented in $\mathrm{ED}_{50}$ and confirmed by the $\mathrm{P}-\mathrm{STAT} 3$ assay 
A

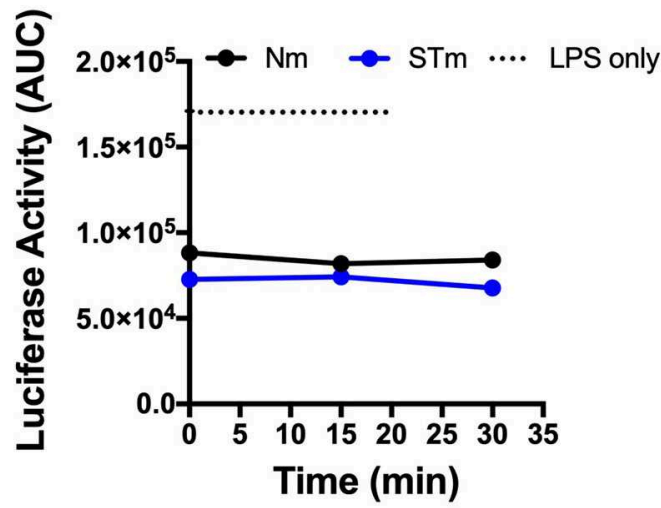

B

Treatment at $55^{\circ} \mathrm{C}$

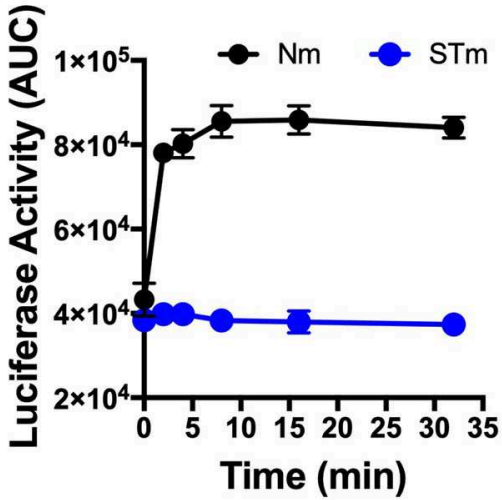

c

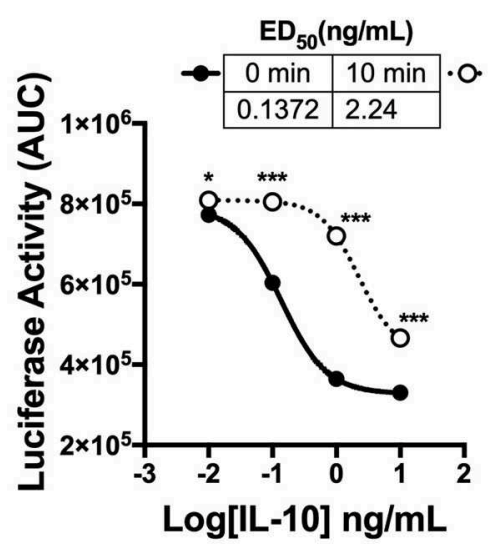

F

pH treatment

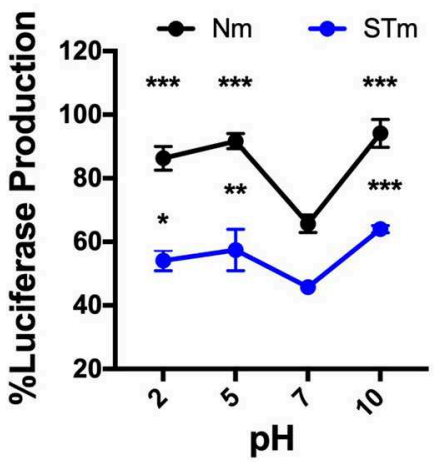

D
$\mathrm{Nm}$

E

STm
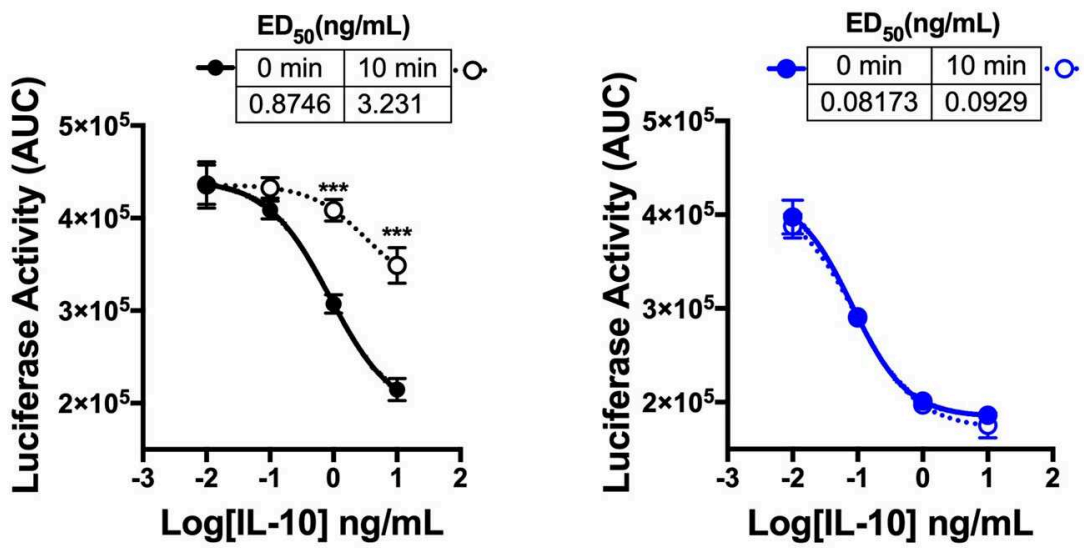

G

Storage at $-80^{\circ} \mathrm{C}$

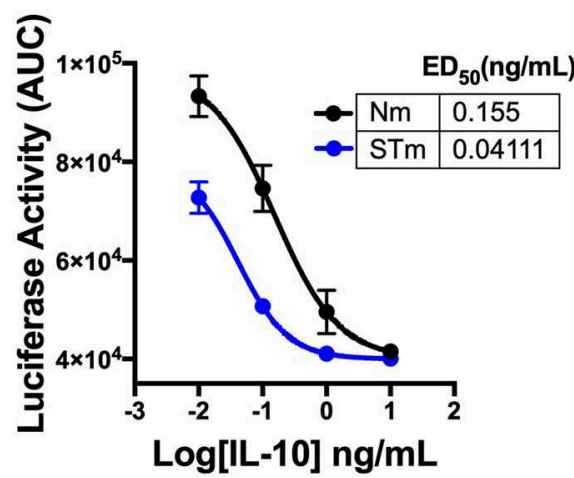

FIGURE 3 | Biological stability of mouse IL-10 variants upon treatment at different temperatures and pH in vitro. (A) Area Under the Curve (AUC) of luciferase induction was measured after incubating $100 \mathrm{ng} / \mathrm{mL} \mathrm{Nm}$ (black line) and STm (blue line) at $37^{\circ} \mathrm{C}$ in the time course. (B) Both Nm (black line) and STm (blue line) were treated at $55^{\circ} \mathrm{C}$ in time course before luciferase activity was measured as the area under the curve (AUC) after LPS-stimulated BMDMs of reporter mouse. (C-E) LPS-induced luciferase inhibition was measured after co-stimulated with either heat-treated at $55^{\circ} \mathrm{C}$ for $10 \mathrm{~min}(10 \mathrm{~min})$ or untreated $(0 \mathrm{~min})$ of the commercial mouse IL-10 (CmlL-10), Nm and STm. CmIL-10 was used as a control in this experiment. The ED 50 was calculated as follow: (C) $\mathrm{CmlL}-10$ heat-treated for (2.24 ng/mL) or 
FIGURE 3 | untreated (0.137); (D) Nm heat-treated for (3.23 ng/mL) or untreated (0.8 ng/mL); (E) STm heat-treated for $(0.09 \mathrm{ng} / \mathrm{mL})$ or untreated (0.08 ng/mL). (F) Both $\mathrm{Nm}$ and STm at $100 \mathrm{ng} / \mathrm{mL}$ were pre-incubated with different pH buffers at $4^{\circ} \mathrm{C}$ for $24 \mathrm{~h}$ flowed by buffer exchange columns. BMDMs of the transgenic mouse then stimulated with LPS $(10 \mathrm{ng} / \mathrm{mL})$, and pH treated IL-10 (Nm and STm) at $10 \mathrm{ng} / \mathrm{mL}$. The percentage of luciferase activities is relative to LPS treatment. The significant difference compared between $\mathrm{pH}$ treatments with neutral $\mathrm{pH}(\mathrm{pH} 7)$ of Nm and STm on LPS-stimulated cells ${ }^{* \star *} p<0.001,{ }^{* *} p<0.005,{ }^{*} p<0.05$; ANOVA. (G) To test the effect of the storage of IL-10 protein in $-80^{\circ} \mathrm{C}$ for 6 months, the $\mathrm{ED}_{50}$ was calculated and compared between Nm (black line) and STm (blue line). All data are representative of three independent experiments, with triplicate cultures per experiment $(N=3, n=3)$, and bars represent standard error of the mean.

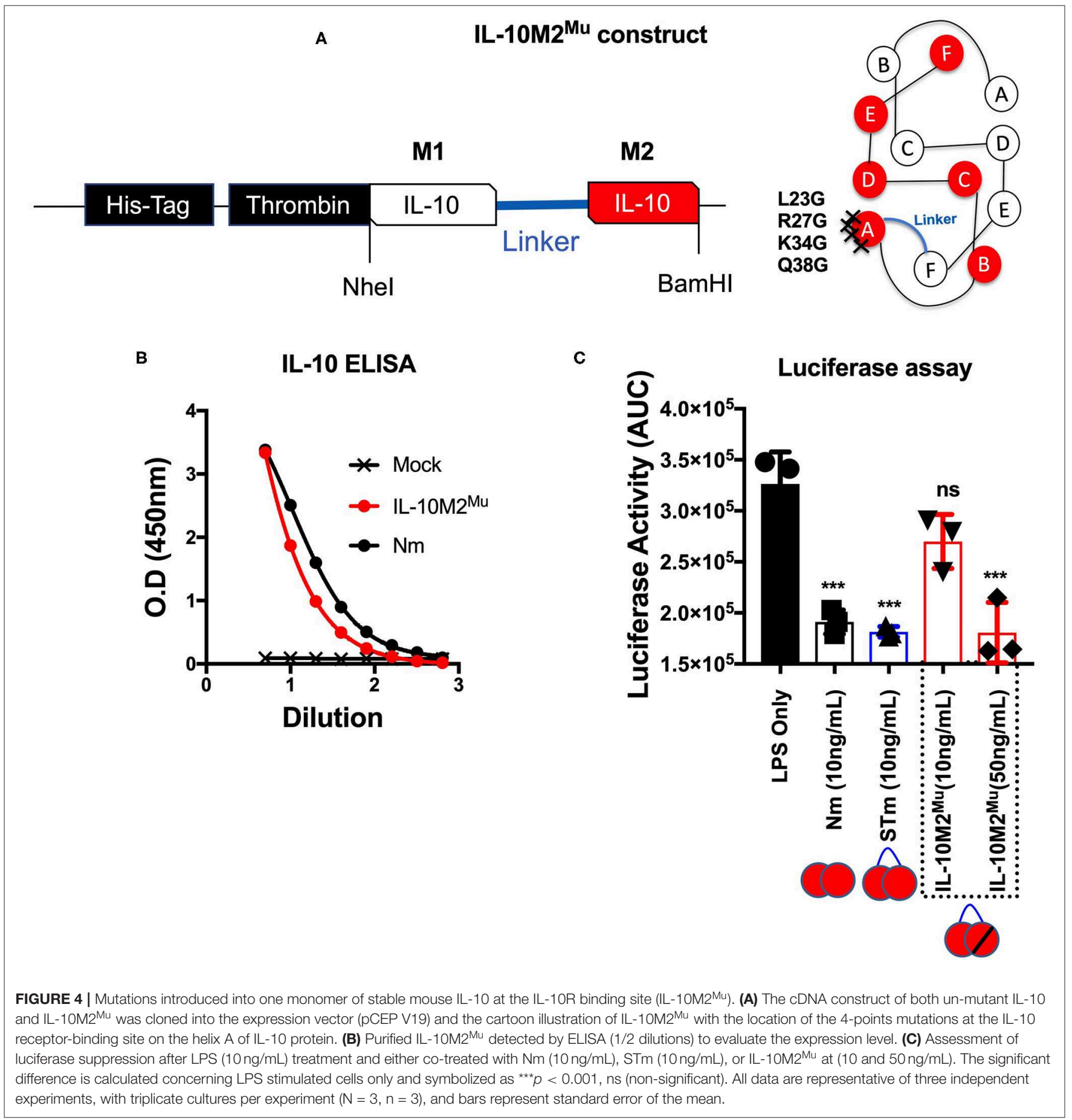

(Figures 5B,C). Based on this data, to further investigate the biological properties and the IL-10R binding of the engineered STm, we assessed the corresponding impact of these substitutions on the biological activity of STm. Our data showed that these mutations affected the biological activity of STm to a different extent compared to $\mathrm{Nm}$, as represented in $\mathrm{ED}_{50}$ and confirmed 
by p-STAT3 assay (Figures 5D,E). Specifically, whereas the ARCHA mutation significantly affected $\mathrm{Nm}$ biological activity by $>500$ fold, this only led to a 10 -fold loss of function in STm. Conversely, the AACHR and RACHR substitutions that did not dramatically modify STm activity led to a similar loss of function in the STm as the ARCHA mutation. Collectively, the inactivation of one monomer of STm led to a weaker binding to IL-10R; moreover, the impact on the biological activity of amino acid substitution at the RRCHR region was higher in $\mathrm{Nm}$ than STm.

\section{Stabilized Mouse IL-10 Dimer Is Biologically Active in vivo}

While the above data demonstrated the improved biological activity and stability of STm in vitro, it was essential also to examine the efficacy of STm in vivo. The efficacy of STm compared to $\mathrm{Nm}$ under physiological conditions was first examined utilizing a local inflammatory reaction in the skin of mice. The skin consists of a multilayer structure of the epidermis, as well as the bluish coloration of the basophilic epithelial cytoplasm (Figures 6A,B). Subcutaneous injection of LPS causes a dose-dependent inflammatory infiltration of all layers of the skin (37). Our previous data showed that this reaction is much more severe in $\mathrm{IL}-10^{-/-}$mice, with considerable necrosis of epidermis, dermis, and panniculus carnosus (37). This result indicates the importance of IL10 in modulating the inflammatory response to LPS in the skin, validating the model to assess the in vivo effectiveness of STm in controlling inflammation. Different concentrations of the IL-10 proteins were injected subcutaneously (under the panniculus carnosus) together with LPS $(10 \mu \mathrm{g})$ into IL$10^{-/-}$mice. On 3 consecutive days, an injection was made in the same place in the flank. On the 5th day, the mice were sacrificed, and the tissue removed from the injection site and examined histologically. This experiment showed that injections of LPS without IL-10 resulted in a massive inflammatory local reaction with massive recruitment of numerous macrophages and neutrophils (Figures 6C,D). Moreover, all layers of the skin in the center of the lesion became necrotic compared to healthy skin. The enlargement view (Figure 6D) showed a necrotic hair follicle and necrotic interfollicular epidermis with condensed nuclei and reddish acidophilic cytoplasm as opposed to the basophilic cytoplasm of healthy keratinocytes. Coadministration of STm along with LPS (Figure 6E) suppressed the inflammatory response in a dose-dependent fashion. In Figure 6F, we summarize the biological activities of STm and $\mathrm{Nm}$ in protecting LPS induced inflammation. Both STm and $\mathrm{Nm}$ were protective at 2 and $0.2 \mu \mathrm{g}$. STm appeared to be more effective than $\mathrm{Nm}$ at $0.02 \mu \mathrm{g}$, where the biological activity of $\mathrm{Nm}$ was waning. At $0.002 \mu \mathrm{g}$, both $\mathrm{Nm}$ and STm had no protective effect against skin inflammation (Figure 6F). This experiment demonstrated the biological effect of STm in vivo but did not allow a quantitative comparison between $\mathrm{Nm}$ and STm.

The activity of STm was also tested using an in vivo model of LPS-induced systemic inflammation. First, the time course of TNF concentration in serum after retro-orbital (i.v.) LPS injection was determined in establishment experiments. A high serum concentration of TNF $\sim 3.2 \mathrm{ng} / \mathrm{mL}$ was measurable $1.5 \mathrm{~h}$ after the administration of LPS ( $25 \mu \mathrm{g}$ i.v.). This value was reduced by about $75 \%$ after $3 \mathrm{~h}$ and had returned close to baseline levels $6 \mathrm{~h}$ after LPS injection. Injections of PBS or Nm and STm $(2 \mu \mathrm{g}$ each) alone did not result in the measurable release of TNF, which could exclude contamination of these reagents with pyrogens (Figure 7A). In the next experiment, different amounts of STm i.v. were injected $30 \mathrm{~min}$ before LPS (25 $\mu$ g i.v.). Here, the STm proved to be highly effective, in a dose-dependent manner, in the suppression of TNF release. The administration of $2 \mu \mathrm{g} \mathrm{Nm}$ and STm reduced serum TNF concentration by $\sim 70 \%$ relative to the control mice receiving only LPS. Both at either 2 or $20 \mu \mathrm{g}$, Nm and STm were equally effective at suppressing TNF production (Figure 7B). Apparently, in this assay, the maximum level of TNF suppression was reached at $2 \mu \mathrm{g}$ IL-10, as the injection of $20 \mathrm{mg}$ IL-10 failed to suppress TNF production further. Experiments with titrations of Nm- and STm, however, showed large fluctuations in TNF serum concentration and therefore did not allow a quantitative comparison of the effects of Nmand STm (data not shown). Therefore, we investigated the ability of Nm and STm IL-10 to inhibit the production of IL6 , which is another cytokine integral within the acute phase inflammatory immune response. The serum concentration of IL-6 was determined $3 \mathrm{~h}$ after injection by ELISA. It was found that over a wide dose range, the STm reduced IL-6 release more effectively than $\mathrm{Nm}$. By non-linear regression, $\mathrm{Nm}$ suppressed the IL-6 response with an $\mathrm{ED}_{50}$ value of $274.8 \mathrm{ng} / \mathrm{mL}$, whereas STm suppressed IL-6 production with an ED50 of $112 \mathrm{ng} / \mathrm{mL}$. Thus, STm was $\sim 2.5$-fold (Figure 7C) more potent than $\mathrm{Nm}$. Altogether, the stable form of IL-10 is biologically active in vivo, which controls both the local and systemic inflammatory responses.

\section{The Biological Activity and Stability of Stabilized Human IL-10 Dimer in vitro}

Our results demonstrated that STm molecules could be generated with potent regulatory activity. Consequently, given the aim of developing an IL-10 based treatment for human disease, we investigated whether it was also possible to create a biologically active and stable version of human IL-10. We first generated and produced a stable human IL-10 using different lengths of the flexible linker (Figure S2A). Our data showed that both $\mathrm{Nh}$ and STh, with different linker lengths, are biologically active in vitro by suppressing LPS-induced luciferase expression in BMDMs from the h.TNF.LucBAC reporter mice (Figure 8A). STh had a 2.5 -fold higher biological activity than $\mathrm{Nh}$, as measured by p-STAT3 activation (Figure 8B), which was confirmed by conventional TNF ELISA assay (Figure S2B). Like the mouse IL-10, the effect of human IL-10 on luciferase suppression was blocked by using mouse anti-IL-10R1 in a dose-dependent manner. Interestingly, our data demonstrate that increased amounts of anti-IL-10R1 antibody were required to block the effect of STh in suppressing luciferase production than to block 


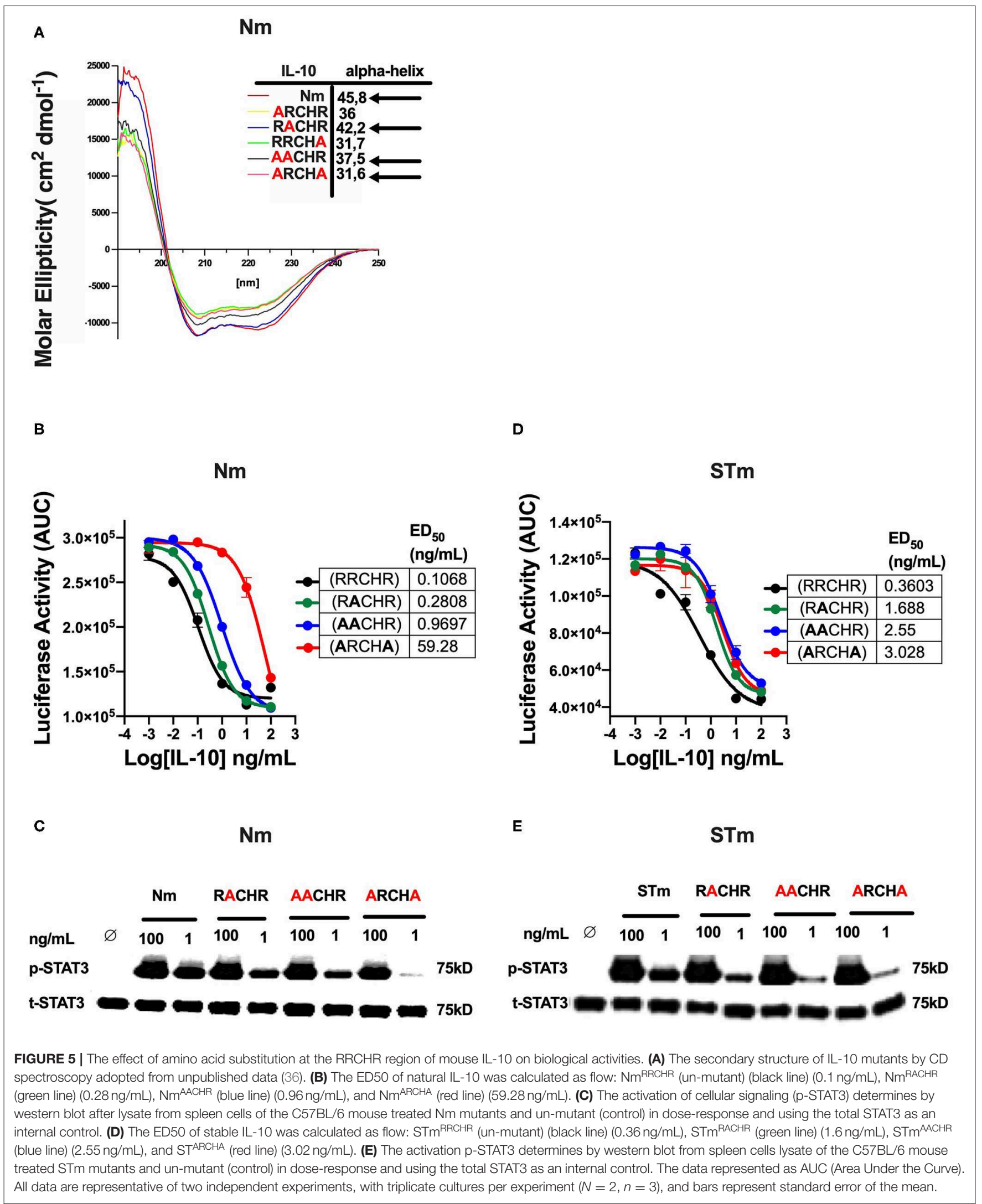


A

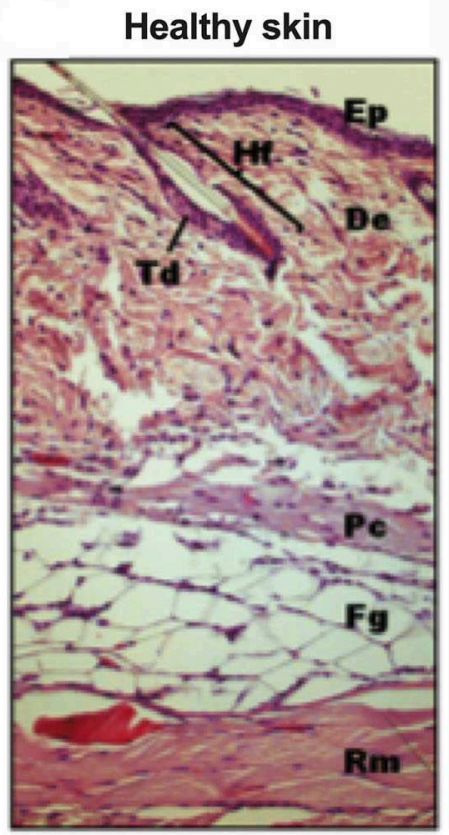

B

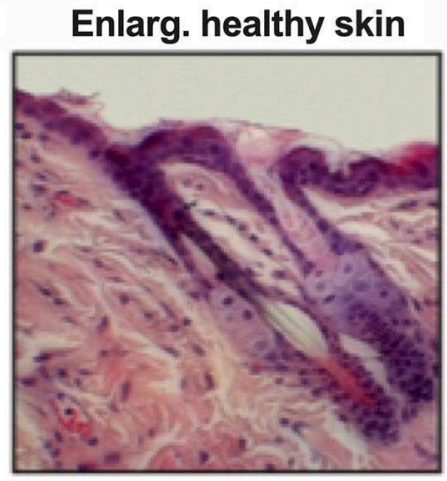

C

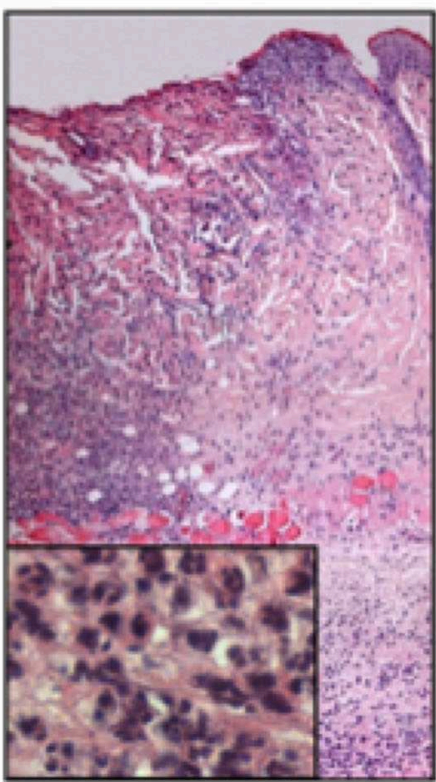

D Enlarg. LPS

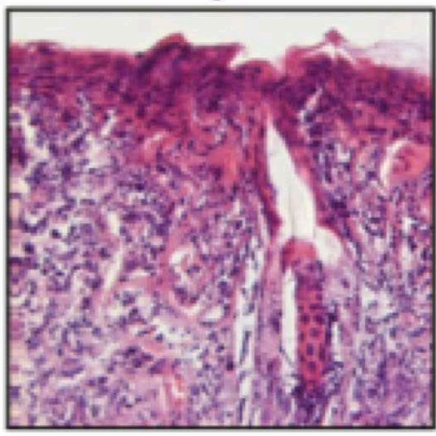

E LPS+STm
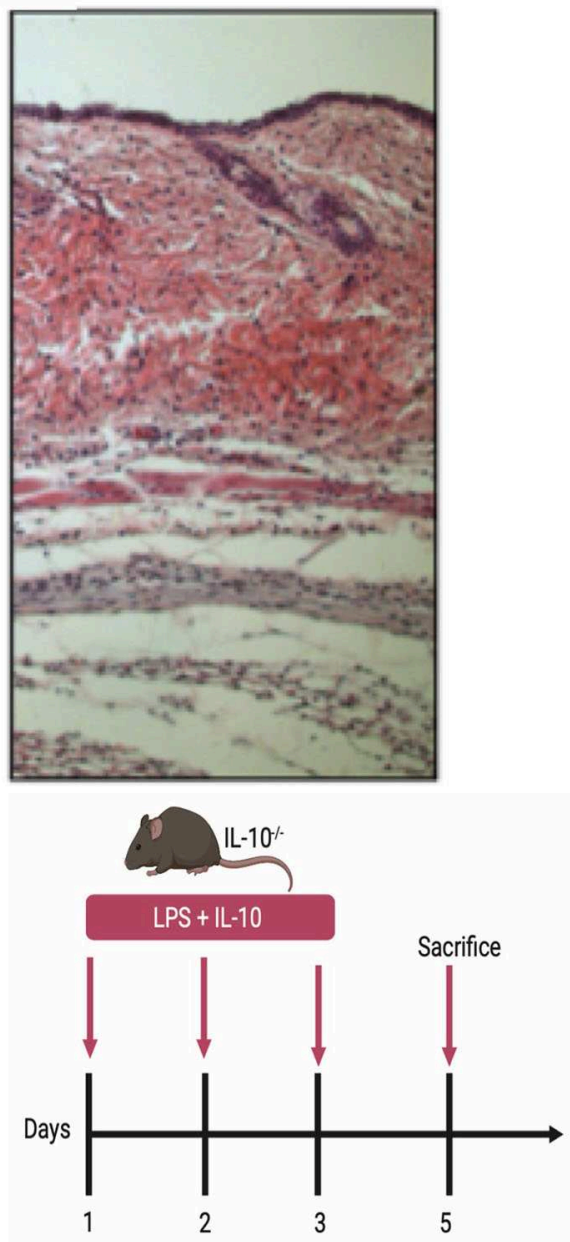

\begin{tabular}{|c|c|c|c|c|c|c|}
\hline $\mathbf{F}$ & $\emptyset \|-10$ & $\begin{array}{c}2 \mu \mathrm{g} \\
\mathrm{Nm} / \mathrm{STm}\end{array}$ & $\begin{array}{c}0.2 \mu \mathrm{g} \\
\mathrm{Nm} / \mathrm{STm}\end{array}$ & \multicolumn{2}{|c|}{$0.02 \mu \mathrm{g}$} & $\begin{array}{l}0.002 \mu \mathrm{g} \\
\mathrm{Nm} / \mathrm{STm}\end{array}$ \\
\hline Necrosis hair follicle & +++ & - & - & ++ & + & +++ \\
\hline Necrosis intrafollicular Epid & +++ & - & - & ++ & - & +++ \\
\hline Necrosis Panniculus carnosus & +++ & - & - & - & - & +++ \\
\hline Inflammatory Infiltrate & +++ & + & ++ & + & + & +++ \\
\hline Infiltrate of Neutrophils & +++ & + & + & + & + & +++ \\
\hline
\end{tabular}

FIGURE 6 | Suppression of LPS-induced dermal inflammation by Nm and STm. (A) Overview of healthy skin. Mouse skin consists of a 1-2-layer epidermis (Ep), which forms the hair follicles $(\mathrm{Hf})$ and sebaceous glands $(\mathrm{Td})$ by invagination in the dermis $(\mathrm{De})$. The dermis consists of collagenous connective tissue. This is followed by the muscle layer of the Panniculus carnosus (Pc), the fatty tissue (Fg), and the trunk muscles (Rm). (B) Enlargement of healthy skin. The epithelium shows bluish cytoplasm and loose chromatin, as well as two intact hair follicles. (C) Overview of necrotic skin. In magnification, a large number of neutrophils is recognizable. (D) Enlargement of necrotic skin. The epithelial cells show reddish cytoplasm and condensed chromatin. The hair follicle is dead. (E) Overview skin section treated STm (2 $\mu \mathrm{g})$ STm, which LPS was co-injected. (F) A table summarizing the effect of IL-10 (Nm/STm) at different concentrations on LPS-treated (10 $\mu \mathrm{g})$ skin. 
A

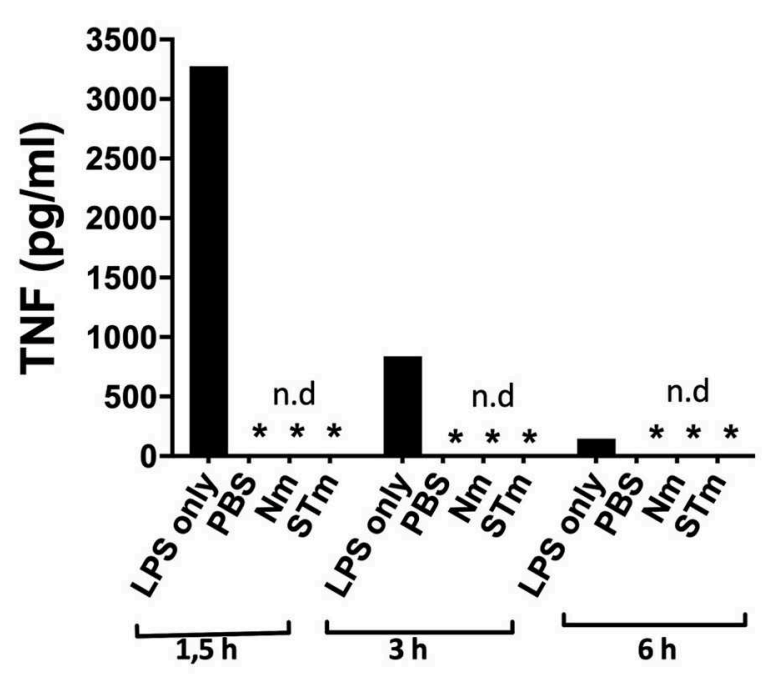

B

\section{TNF ELISA}

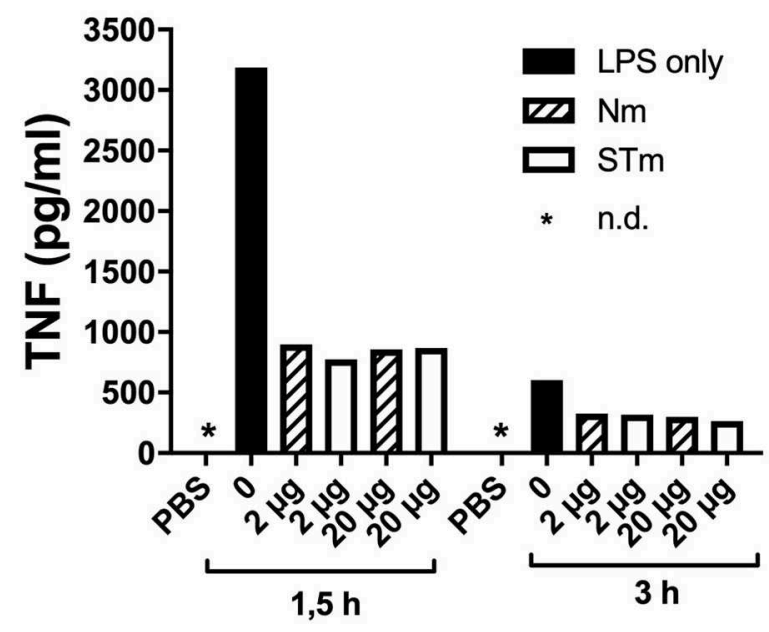

C

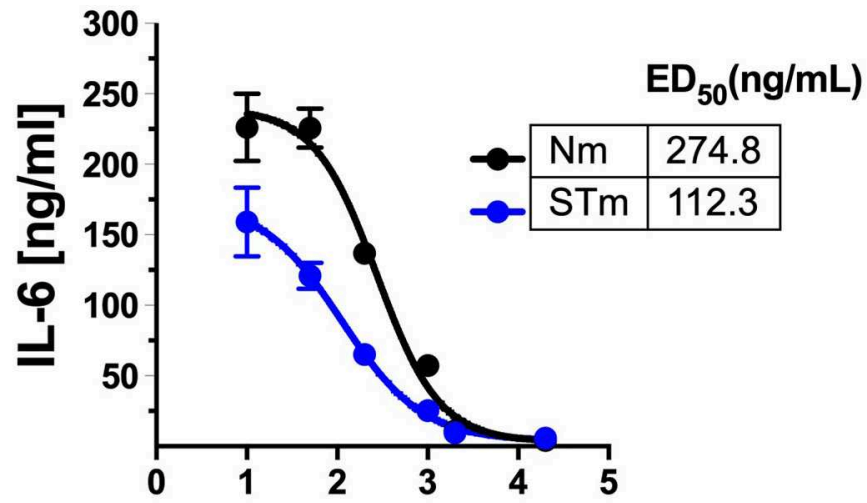

Log[lL-10] ng/mL

FIGURE 7 | Detection of the in vivo activity of the STm by suppression of LPS-induced cytokine release. (A,B) $100 \mu$ I PBS containing $25 \mu \mathrm{g}$ LPS i.v. Injected in C57BL/6 mice (8-12 weeks). At the indicated time points, blood was taken retro-orbitally, and ELISA determined the TNF-a serum concentration, ${ }^{*}$.d.: not detectable. (A) To establish, LPS, PBS, Nm, or STm (2 $\mu \mathrm{g}$ protein each) were injected one at a time. (B) 30 min before LPS administration, the indicated amounts of Nm or STm were i.v. Injected. (C) IL-10 -/- mice were given $10 \mu \mathrm{g}$ LPS together with increasing concentrations of Nm or STm i.v. Injected. After $3 \mathrm{~h}$, blood was drawn, and the IL 6 serum concentration determined by ELISA.

the effect of Nh (Figure 8C). This data may indicate the binding of STh to mouse IL-10R is of higher affinity compared to the Nh.

In terms of stability, both STh and Nh were incubated during a time course at $37^{\circ} \mathrm{C}$, which showed no significant difference in luciferase inhibition ( $p>0.5$, ANOVA) (Figure 8D), which indicates the both $\mathrm{Nh}$ and STh are biologically active at physiological temperature. However, Nh gradually lost biological activity after $5 \mathrm{~min}$ of heat treatment at $55^{\circ} \mathrm{C}$, whereas $\mathrm{STh}$ maintained biological activity as measured by luciferase assay (Figure 8E) and TNF-ELISA (Figure S1B). In a dose-response experiment, we also observed that $\mathrm{Nh}$ became less potent 


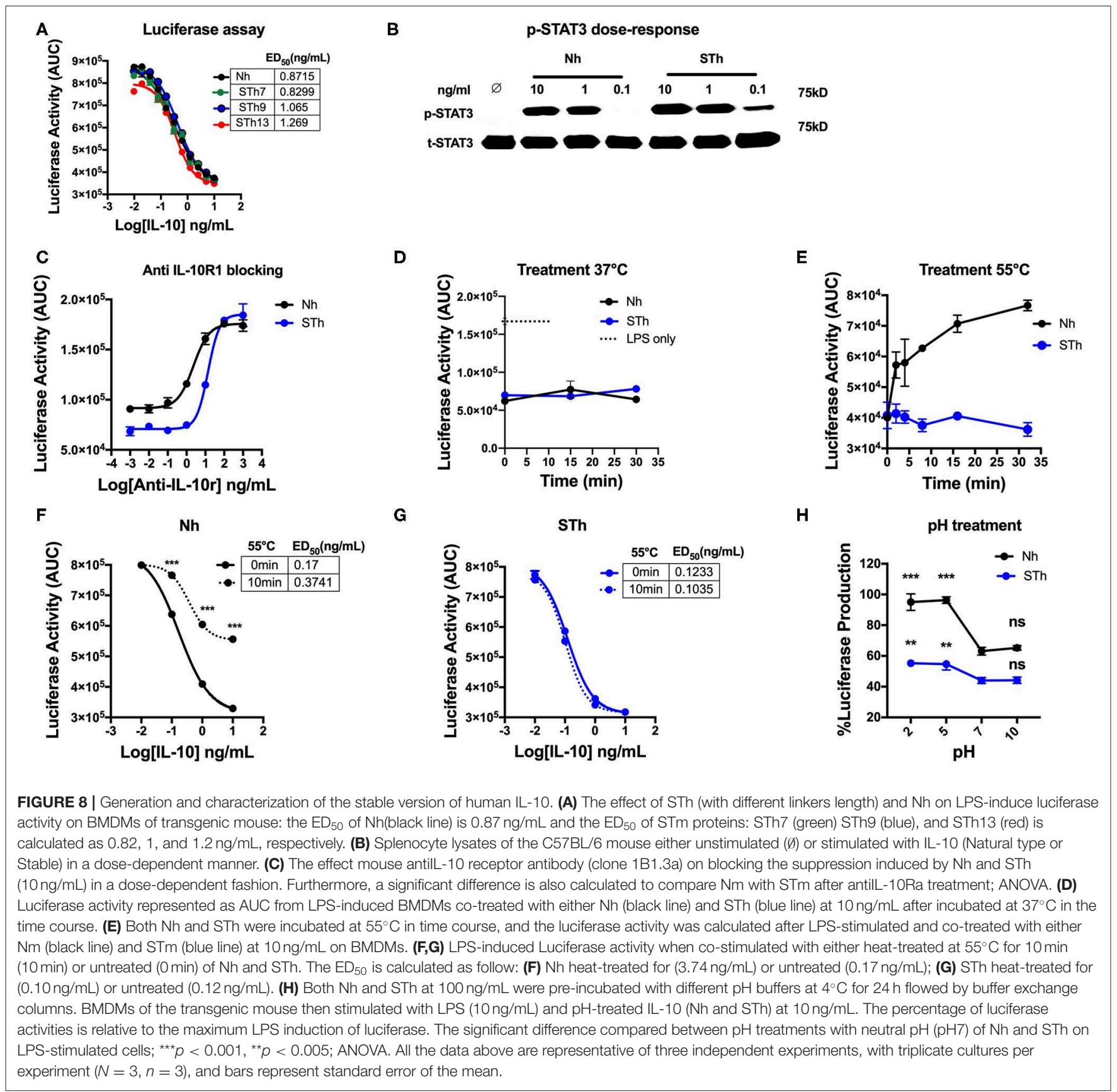

after heat treatment $\left(55^{\circ} \mathrm{C}\right.$ for $10 \mathrm{~min}$ ) (Figure 8F); however, $\mathrm{STh}$ maintained suppressive activity (Figure 8G). The $\mathrm{pH}-$ dependent stability study showed that STh behave similarly to $\mathrm{Nh}$, but, the $\mathrm{STh}$ was more resistant in $\mathrm{pH} 5$ and $\mathrm{pH} 2$ (Figure 8H). Overall, these data show that the STh is a biologically active protein in vitro with higher stability compared to Nh.

Overall, we generate a stable IL-10 dimer by linking two IL-10 monomers in a head to tail fashion by a flexible linker (Figure 9). We demonstrate that our novel stable IL-10 dimer is more stable in different stress conditions compared to non-covalently linked
IL-10 (i.e., natural IL-10). We assume the stable IL-10 dimer folds as natural IL-10. The IL-10 3D domain-swapped dimerization of IL-10 is essential to form the receptor binding site of the cytokine (13). Our mutational experiment has indirectly proved that stable IL-10 dimer binds and acts by the IL-10 receptor.

\section{DISCUSSION}

Soon after the cytokine IL-10 was cloned, we generated a mouse mutant deficient for IL-10 and could show that these 


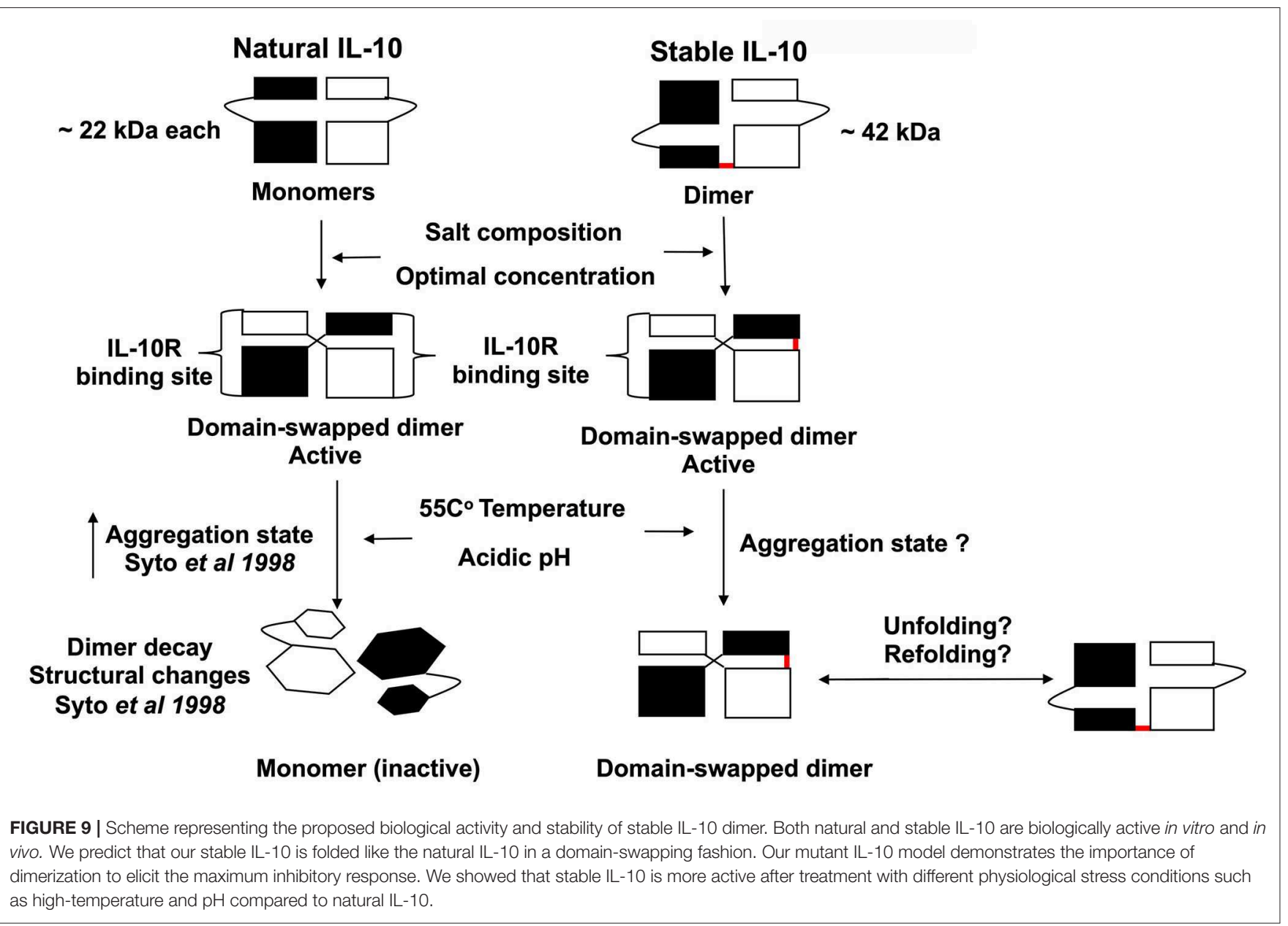

mice developed inflammatory bowel disease that depended on the microflora (21). Based on these findings and subsequent preclinical trials, it was shown that while recombinant IL-10 was safe and well-tolerated in healthy individuals (38), it had limited efficacy in treating inflammatory diseases (39). In this report, we reach an important milestone for the generation of a recombinant IL-10 with more stable biochemical properties. Syto et al. studied the structural and biological stability of non-covalently linked IL-10 dimer under different conditions. It was observed that incubation of human IL-10 dimer for $1 \mathrm{~h}$ at 37 and $55^{\circ} \mathrm{C}$ resulted in the formation of 2 and $22 \%$ monomers, respectively (9). By the covalent fusion of two IL10 monomers, we generated a more stable and most likely also more biologically active form of IL-10 both for mouse and human (Figures 2, 8). The previous study demonstrates that the covalent fusion of dimeric HIV-1 proteases has been shown to improve protein stability compared to natural dimer (30). However, the mechanism of this stability enhancement is not clear. Our possible explanation is that linking the Cterminus of one IL-10 monomer to the N-terminus of the second monomer may increase the stability of the IL-10 3D domain-swapped dimer. The IL-10 3D domain-swapped dimer defined as the exchange of the helices $\mathrm{E}$ and $\mathrm{F}$ (from the first monomer) into the hydrophobic cleft (helices A-D) of the other monomer, which may not be profoundly affected by the different conditions of stress in stable IL-10 compared to the natural IL10. This study did not define the potential of refolding stable IL-10 to the known active state after different stress-inducing conditions were applied. We could demonstrate that the new IL-10 dimer binds and acts via the IL-10 receptor, shown that it does not act on IL10R1 deficient lymphocytes (Figure 2A), by blocking the biological activity using anti-IL-10 receptor antibodies (Figure 2F) and by introducing point mutations in the covalent linked IL-10 dimer suggested to be involved in IL10 and IL-10 receptor interaction (Figure 4). A previous study suggested that IL-10 dimer formation is vital to generate the receptor-binding domain that activates IL-10R signaling via side to side interaction (13). Therefore, it is believed that the correct dimer formation (i.e., 3D domain swapping) in IL-10 is essential to create a receptor-binding domain (13). This hypothesis has been confirmed by generating a stable monomeric form as a model to bind to IL-10R in 1:1 interaction (40). The next step 
along this line is to generate crystal structures for the new IL10 proteins and to compare these to the known IL-10 structure (33). Our recombinant stable dimeric IL-10 can now be used as a building block for the development of IL-10 based therapeutic. One of the new features of our stable IL-10 is that we can now prepare asymmetric IL-10 variants as we have control over the complete IL-10 dimer. We can modify each IL-10 molecule in the dimer independently and get $100 \%$ variants with a defined order of each of the monomers. This allows in the future more insights into the functional analysis of IL-10 with its receptor and fine-tuning of the biological activity of the stable IL-10 protein.

Using the conditional gene targeting approach, we generated mouse mutants with selective gene inactivation of the IL10 (41) and the IL-10R (23). Using these mutants in many different settings, we have clear evidence that IL-10 is a local acting cytokine, and there is an apparent cell-type specificity at both at the level of the IL-10 producing and at the level of the IL-10 responding cell. For example, in the Tcell specific IL-10 deficient mouse mutant (41), only T cellspecific responses are dysregulated, while innate responses are unaffected. In contrast, in a macrophage-specific IL-10 receptordeficient mouse mutant, the $\mathrm{T}$ cell responses are unaffected while innate responses are disturbed similarly to IL-10 ${ }^{-/-}$mice. These experiments suggest that the next step toward an IL10 based therapeutic recombinant protein will be to make an IL-10 protein that can mimic the local acting property of IL10.This might be achieved by joining our recombinant stable IL-10 to other protein domains that can bind to local regions and/or to specific cell types. Of note, we have generated a fusion protein of IL-10 with an antibody and could see that both the IL-10 activity and the antibody binding property is present in the fusion protein (work in progress). One of the challenging steps in the engineering is to use a form of IL-10 that is less active compared to the natural IL-10 protein in order to allow IL-10 action only when a high local concentration of IL-10 through the local accumulation of the IL-10 protein through the antibody part. Examples of such IL10 weakening mutations are presented in this report (Figure 4). We presume that we are maybe even able to generate a local acting IL-10 inhibitor, in which one of the two dimers is mutated in a way that the stable IL-10 dimer binds to one of the IL-10 receptor chains and blocking dimerization of the receptor.

In conclusion, the effect of IL-10 in clinical trials is limited due to pleiotropic properties on different cells, and the rapid dissociation of the homodimer at the site of inflammation. Our stable IL-10 protein could be a potential building block for generating a potent and more effective and selective IL-10-based immunotherapy for treating inflammatory diseases and cancers. For instance, a stable IL-10 dimer has already been proposed as a model for generating a target IL-10 immunotherapy because it has a higher biological activity compared to the natural IL-10 monomer (42) and the IL-10 dimer proposed here would allow constructing such cell-type-specific local acting IL-10.

\section{DATA AVAILABILITY STATEMENT}

All datasets generated for this study are included in the article/Supplementary Material.

\section{ETHICS STATEMENT}

The animal study was reviewed and approved by Home Office project license (70/7800) (P8829D3B4) in agreement with the Animal (Scientific Procedures) Act 1986 and the in vivo experiments were performed at the University of Cologne, Germany, under animal experimental license 24-9168.11-1/2009-22.

\section{AUTHOR CONTRIBUTIONS}

FM, SL, AR, and WM: conception, design, and stable IL-10 construction. FM and SL: in vitro experiment. SL and AR: in vivo experiments. FM, SL, and WM: data acquisition. FM, SL, RJ, and EM: IL-10 expression. FM and SP: luciferase assay. FM, SL, SP, $\mathrm{KC}, \mathrm{AR}$, and WM: data analysis and interpretation. FM, KC, and WM: drafting of the article. All co-authors: final approval of the manuscript.

\section{FUNDING}

The work was supported by a Ph. D. scholarship from Umm AlQura University, Saudi Arabia (UMU740) to FM and by the MRC (MR/R010099/1) to KC. MR/R010099/1 was jointly funded by the UK Medical Research Council (MRC) and the UK Department for International Development (DFID) under the MRC/DFID Concordat agreement and is also part of the EDCTP2 program supported by the European Union.

\section{ACKNOWLEDGMENTS}

We would like to express our deep and sincere gratitude to Prof. Dr. Mats Paulsson (University of Cologne) for his contribution to this study by providing the mammalian expression vector and cell lines. We also would like to thank Prof. Mike White (University of Manchester) for using the illuminance measuring instrument. We also acknowledge the support and advice from all members in Transgenic Unit core facility (TgU), Faculty of Biology, Medicine and Health, University of Manchester.

\section{SUPPLEMENTARY MATERIAL}

The Supplementary Material for this article can be found online at: https://www.frontiersin.org/articles/10.3389/fimmu. 2020.01794/full\#supplementary-material 


\section{REFERENCES}

1. Boonstra A, Rajsbaum R, Holman M, Marques R, Asselin-Paturel C, Pereira JP, et al. Macrophages and myeloid dendritic cells, but not plasmacytoid dendritic cells, produce IL-10 in response to MyD88- and TRIF-dependent TLR signals, TLR-independent signals. J Immunol. (2006) 177:7551-8. doi: 10.4049/jimmunol.177.11.7551

2. Fujita S, Seino K, Sato K, Sato Y, Eizumi K, Yamashita N, et al. Regulatory dendritic cells act as regulators of acute lethal systemic inflammatory response. Blood. (2006) 107:3656-64. doi: 10.1182/blood-2005-10-4190

3. Comi M, Amodio G, Gregori S. Interleukin-10-producing DC-10 is a unique tool to promote tolerance via antigen-specific T regulatory type 1 cells. Front Immunol. (2018) 9:682. doi: 10.3389/fimmu.2018.00682

4. Barthlott T, Moncrieffe H, Veldhoen M, Atkins CJ, Christensen J, O'Garra A, et al. CD25 + CD4 $+\mathrm{T}$ cells compete with naive CD4 $+\mathrm{T}$ cells for IL2 and exploit it for the induction of IL-10 production. Int Immunol. (2005) 17:279-88. doi: 10.1093/intimm/dxh207

5. Ouyang W, O'Garra A. IL-10 family cytokines IL-10 and IL22: from basic science to clinical translation. Immunity. (2019) 50:871-91. doi: 10.1016/j.immuni.2019.03.020

6. Zdanov A, Schalk-Hihi C, Gustchina A, Tsang M, Weatherbee J, Wlodawer A. Crystal structure of interleukin-10 reveals the functional dimer with an unexpected topological similarity to interferon gamma. Structure. (1995) 3:591-601. doi: 10.1016/S0969-2126(01)00193-9

7. Walter MR. The molecular basis of IL-10 function: from receptor structure to the onset of signaling. Curr Top Microbiol Immunol. (2014) 380:191212. doi: 10.1007/978-3-662-43492-5_9

8. Walter MR, Nagabhushan TL. Crystal structure of interleukin 10 reveals an interferon gamma-like fold. Biochemistry. (1995) 34:12118-25. doi: 10.1021/bi00038a004

9. Syto R, Murgolo NJ, Braswell EH, Mui P, Huang E, Windsor WT. Structural and biological stability of the human interleukin 10 homodimer. Biochemistry. (1998) 37:16943-51. doi: 10.1021/bi981555y

10. Liu Y, Wei SH, Ho AS, de Waal Malefyt R, Moore KW. Expression cloning and characterization of a human IL-10 receptor. J Immunol. (1994) 152:1821-9.

11. Ozaki K, Leonard WJ. Cytokine and cytokine receptor pleiotropy and redundancy. J Biol Chem. (2002) 277:29355-8. doi: 10.1074/jbc.R200003200

12. Tan JC, Indelicato SR, Narula SK, Zavodny PJ, Chou CC. Characterization of interleukin-10 receptors on human and mouse cells. J Biol Chem. (1993) 268:21053-9.

13. Josephson K, Logsdon NJ, Walter MR. Crystal structure of the IL-10/IL-10R1 complex reveals a shared receptor binding site. Immunity. (2001) 15:3546. doi: 10.1016/S1074-7613(01)00169-8

14. Riley JK, Takeda K, Akira S, Schreiber RD. Interleukin-10 receptor signaling through the JAK-STAT pathway. Requirement for two distinct receptorderived signals for anti-inflammatory action. J Biol Chem. (1999) 274:1651321. doi: $10.1074 /$ jbc.274.23.16513

15. Clarke CJ, Hales A, Hunt A, Foxwell BM. IL-10-mediated suppression of TNF-alpha production is independent of its ability to inhibit NF kappa B activity. Eur J Immunol. (1998) 28:171926. doi: 10.1002/(SICI)1521-4141(199805)28:05<1719::AID-IMMU1719>3. $0 . \mathrm{CO} ; 2-\mathrm{Q}$

16. Peranteau WH, Zhang L, Muvarak N, Badillo AT, Radu A, Zoltick PW, et al. IL-10 overexpression decreases inflammatory mediators and promotes regenerative healing in an adult model of scar formation. J Invest Dermatol. (2008) 128:1852-60. doi: 10.1038/sj.jid.57 01232

17. Wilson EH, Wille-Reece U, Dzierszinski F, Hunter CA. A critical role for IL-10 in limiting inflammation during toxoplasmic encephalitis. J Neuroimmunol. (2005) 165:63-74. doi: 10.1016/j.jneuroim.2005.04.018

18. Bekker LG, Maartens G, Steyn L, Kaplan G. Selective increase in plasma tumor necrosis factor-alpha and concomitant clinical deterioration after initiating therapy in patients with severe tuberculosis. J Infect Dis. (1998) 178:5804. doi: 10.1086/517479

19. Suvas S, Azkur AK, Kim BS, Kumaraguru U, Rouse BT. CD4+CD25+ regulatory $\mathrm{T}$ cells control the severity of viral immunoinflammatory lesions. J Immunol. (2004) 172:4123-32. doi: 10.4049/jimmunol.172.7.4123
20. Couper KN, Blount DG, Riley EM. IL-10: the master regulator of immunity to infection. J Immunol. (2008) 180:5771-7. doi: 10.4049/jimmunol.180.9.5771

21. Kuhn R, Lohler J, Rennick D, Rajewsky K, Muller W. Interleukin10-deficient mice develop chronic enterocolitis. Cell. (1993) 75:26374. doi: 10.1016/0092-8674(93)80068-P

22. Zigmond E, Bernshtein B, Friedlander G, Walker CR, Yona S, Kim KW, et al. Macrophage-restricted interleukin-10 receptor deficiency, but not IL10 deficiency, causes severe spontaneous colitis. Immunity. (2014) 40:72033. doi: 10.1016/j.immuni.2014.03.012

23. Pils MC, Pisano F, Fasnacht N, Heinrich JM, Groebe L, Schippers A, et al. Monocytes/macrophages and/or neutrophils are the target of IL10 in the LPS endotoxemia model. Eur J Immunol. (2010) 40:4438. doi: 10.1002/eji.200939592

24. Sellon RK, Tonkonogy S, Schultz M, Dieleman LA, Grenther W, Balish $\mathrm{E}$, et al. Resident enteric bacteria are necessary for development of spontaneous colitis and immune system activation in interleukin-10-deficient mice. Infect Immun. (1998) 66:5224-31. doi: 10.1128/IAI.66.11.5224-52 31.1998

25. Steen $\mathrm{KH}$, Steen AE, Reeh PW. A dominant role of acid $\mathrm{pH}$ in inflammatory excitation and sensitization of nociceptors in rat skin, in vitro. J Neurosci. (1995) 15:3982-9. doi: 10.1523/JNEUROSCI.15-05-03982.1995

26. Punnia-Moorthy A. Evaluation of $\mathrm{pH}$ changes in inflammation of the subcutaneous air pouch lining in the rat, induced by carrageenan, dextran and Staphylococcus aureus. J Oral Pathol. (1987) 16:36-44. doi: 10.1111/j.1600-0714.1987.tb00674.x

27. Punnia-Moorthy A. Buffering capacity of normal and inflamed tissues following the injection of local anaesthetic solutions. Br J Anaesth. (1988) 61:154-9. doi: 10.1093/bja/61.2.154

28. Roers A, Lanvermann S, Müller W. Covalently Linked Interleukin-10. Google Patents, US (2013).

29. Chen X, Zaro JL, Shen WC. Fusion protein linkers: property, design and functionality. Adv Drug Deliv Rev. (2013) 65:135769. doi: 10.1016/j.addr.2012.09.039

30. Cheng YS, Yin FH, Foundling S, Blomstrom D, Kettner CA. Stability and activity of human immunodeficiency virus protease: comparison of the natural dimer with a homologous, single-chain tethered dimer. Proc Natl Acad Sci USA. (1990) 87:9660-4. doi: 10.1073/pnas.87.24.9660

31. Foss TR, Kelker MS, Wiseman RL, Wilson IA, Kelly JW. Kinetic stabilization of the native state by protein engineering: implications for inhibition of transthyretin amyloidogenesis. J Mol Biol. (2005) 347:84154. doi: 10.1016/j.jmb.2005.01.050

32. Minshawi F, White MRH, Muller W, Humphreys N, Jackson D, Campbell BJ, et al. Human TNF-Luc reporter mouse: a new model to quantify inflammatory responses. Sci Rep. (2019) 9:193. doi: 10.1038/s41598-01836969-x

33. Zdanov A, Schalk-Hihi C, Wlodawer A. Crystal structure of human interleukin-10 at $1.6 \mathrm{~A}$ resolution and a model of a complex with its soluble receptor. Protein Sci. (1996) 5:1955-62. doi: 10.1002/pro.55600 51001

34. Reddy Chichili VP, Kumar V, Sivaraman J. Linkers in the structural biology of protein-protein interactions. Protein Sci. (2013) 22:153-67. doi: 10.1002/pro.2206

35. Soderquist RG, Milligan ED, Harrison JA, Chavez RA, Johnson KW, Watkins LR, et al. PEGylation of interleukin-10 for the mitigation of enhanced pain states. J Biomed Mater Res A. (2010) 93:1169-79. doi: 10.1002/jbm.a.32611

36. Lanvermann S. Die Bedeutung von Stabilität und Matrixinteraktion des immunsuppressiven Zytokins Interleukin-10 für seine biologischen Effekte, Dresden: Der Technischen Universität Dresden (2014).

37. Siewe L, Bollati-Fogolin M, Wickenhauser C, Krieg T, Muller W, Roers A. Interleukin-10 derived from macrophages and/or neutrophils regulates the inflammatory response to LPS but not the response to CpG DNA. Eur J Immunol. (2006) 36:3248-55. doi: 10.1002/eji.200636012

38. Asadullah K, Sterry W, Volk HD. Interleukin-10 therapy-review of a new approach. Pharmacol Rev. (2003) 55:241-69. doi: 10.1124/pr.55.2.4

39. $\mathrm{Li} \mathrm{MC}, \mathrm{He} \mathrm{SH}$. IL-10 and its related cytokines for treatment of inflammatory bowel disease. World J Gastroenterol. (2004) 10:620-5. doi: 10.3748/wjg.v10.i5.620 
40. Josephson K, DiGiacomo R, Indelicato SR, Iyo AH, Nagabhushan TL, Parker $\mathrm{MH}$, et al. Design and analysis of an engineered human interleukin10 monomer. J Biol Chem. (2000) 275:13552-7. doi: 10.1074/jbc.275.18. 13552

41. Roers A, Siewe L, Strittmatter E, Deckert M, Schluter D, Stenzel W, et al. T cell-specific inactivation of the interleukin 10 gene in mice results in enhanced $\mathrm{T}$ cell responses but normal innate responses to lipopolysaccharide or skin irritation. J Exp Med. (2004) 200:1289-97. doi: 10.1084/jem.20041789

42. Qiao J, Liu Z, Dong C, Luan Y, Zhang A, Moore C, et al. Targeting tumors with IL-10 prevents dendritic cell-mediated $\mathrm{CD} 8^{+} \mathrm{T}$ cell apoptosis. Cancer Cell. (2019) 35:901-15.e4. doi: 10.1016/j.ccell.2019.05.005
Conflict of Interest: The authors declare that the research was conducted in the absence of any commercial or financial relationships that could be construed as a potential conflict of interest.

Copyright (C) 2020 Minshawi, Lanvermann, McKenzie, Jeffery, Couper, Papoutsopoulou, Roers and Muller. This is an open-access article distributed under the terms of the Creative Commons Attribution License (CC BY). The use, distribution or reproduction in other forums is permitted, provided the original author(s) and the copyright owner(s) are credited and that the original publication in this journal is cited, in accordance with accepted academic practice. No use, distribution or reproduction is permitted which does not comply with these terms. 